\title{
Evaluating thermal losses and storage capacity in high-temperature aquifer thermal energy storage (HT-ATES) systems with well operating limits: insights from a study-case in the Greater Geneva Basin, Switzerland
}

\author{
M. Collignon ${ }^{1}$ \\ Ø. S. Klemetsdal ${ }^{2,3}$ \\ O. Møyner ${ }^{2,3}$ \\ M. Alcanié ${ }^{1}$
}

A. P. Rinaldi ${ }^{4} \quad$ H. Nilsen ${ }^{3} \quad$ M. Lupi ${ }^{1}$

1. Department of Earth Sciences, University of Geneva, Switzerland.

2. Norwegian University of Science and Technology, Trondheim, Norway.

3. SINTEF Digital, Oslo, Norway.

4. Swiss Seismological Service, ETH Zurich, Switzerland.

\begin{abstract}
High-temperature aquifer thermal energy storage (HT-ATES) may play a key role in the development of sustainable energies and thereby in the overall reduction of $\mathrm{CO}_{2}$ emission. To this end, a thorough understanding of the thermal losses associated with HT-ATES is crucial. We provide in this study a numerical investigation of the thermal performance of an HT-ATES system for a heterogeneous aquifer modelled after a well-defined region in the Greater Geneva Basin (Switzerland), where the excess heat produced by a nearby waste-to-energy plant is available for storage. We consider different aquifer properties and flow conditions, with complex injection strategies that respect maximum/minimum well pressures and temperatures, as well as legal regulations. Based on the results, we also draw conclusions on the economical feasibility (e.g., energy recovery factor vs. drilling costs) for the different strategies.

Our results indicate that the true behaviour of HT-ATES systems may deviate significantly from theoretical performance derived from idealised cases. This is particularly true when the operational pressure and temperature ranges of the wells are restricted, and for heterogeneous aquifers.
\end{abstract}

keywords: Numerical Modelling; HT-ATES; Greater Geneva Basin 


\section{1 Introduction}

Global warming and pollution caused by industrial gas emissions and wastes urge for a rapid development of renewable energies and application of sustainable development policies (Colombo, 1992; Dincer, 1998; Hähnlein et al., 2013). A notable disadvantage of renewable and/or recycled energy compared to fossil fuels is the seasonal imbalance between the energetic demand and the production or availability of energy seen in regions of contrasted seasons (Dincer and Rosen, 2011). This results in an energy deficit and excess in winters and summers, respectively. Storing the excess of energy in the subsurface and exploit it later when needed, otherwise known as underground thermal energy storage (UTES), helps to buffer the seasonal imbalance and significantly contribute to reduce greenhouse gas emissions (Dincer, 2000; Andersson, 2007; Buscheck et al., 2017). Among the different UTES systems, aquifer thermal energy storage (ATES) is a cost-effective and suitable technology to store large amounts of energy, and has been increasingly used for heating and cooling of buildings (Bloemendal et al., 2014; Sommer et al., 2015; Schüppler et al., 2019). An ATES system stores sensible heat in an aquifer by injecting and withdrawing groundwater and often operates in a seasonal mode (Dickinson et al., 2009; Sommer et al., 2013). Cool groundwater is extracted through a cold well in summer to cool down buildings, while heated water is stored in the aquifer using a warm well at a different location. In wintertime the system is reversed: the heated water is extracted at the warm well to heat up buildings, while cool water is injected back into the aquifer at the cold well. Most of ATES systems store low-temperature groundwater (LT-ATES) in a range of 5 to $30^{\circ} \mathrm{C}$ (Drijver et al., 2012). High-temperature ATES (HT-ATES, T $>60^{\circ} \mathrm{C}$ ) systems in contrast are limited due to legal aspects, often related to the restrictions on temperature increase during geothermal exploitation (Hähnlein et al., 2010; Drijver et al., 2012). Moreover, the first pilot studies reported increasing technical problems in wells (Jenne et al., 1992; Sanner, 1999) and a lower thermal recovery efficiency compared to LT-ATES systems (Molz et al., 1979, 1983a,b). Yet, HT-ATES systems possess a main advantage over LT-ATES systems since the stored energy can directly be used for heating purposes without the need for additional heat-pumps and are suitable for more applications (Drijver et al., 2012). Large amounts of heat from industrial residual waste, such as from incinerators and electricity plants, could then be stored in HT-ATES systems. These advantages combined with the rising energy prices and improvements in well and UTES technology (Van Lopik et al., 2016) have triggered a renewed interest in HT-ATES.

Besides legal regulations, one of the limiting aspects of HT-ATES are the thermal losses due to conduction and convection, which are aggravated with increasing injection temperatures. Previous studies established links between the thermal losses and the aquifer and injected water properties, or the aspect ratio of the volume of stored warm water (Hellström et al., 1979; Doughty et al., 1982; Bloemendal and Hartog, 2018). Free convection due to buoyancy forces during heat storage remains limited for low- to moderate-permeability aquifers (Hellström et al., 1979). However, low- to moderate-permeability aquifers 
require adequate scaling of injection and production rates during the loading and unloading phases, respectively, to avoid rock fracturing and thus the loss of the entire heat stock. As a results, the volume of injected/produced warm water is smaller, or the loading/unloading phases need to be longer. Therefore, an appropriated balance between thermal losses and storage capacity needs to be evaluated when planning an HT-ATES system. The suitability of an ATES project is determined by its economical gain and compliance with legal regulations and thus requires a detailed characterisation of both the aquifer and aquiclude geology and physical properties, as well as the groundwater chemistry and flow characteristics (Andersson, 2007). Such assessments can be complex, and the use of numerical models has become a standard procedure in the evaluation and design optimisation of ATES projects. (O'Sullivan et al., 2000; Lee, 2010). Despite their complexity, many studies often consider equal and constant injected and produced volumes, and do not mention any scaling of rates as a function of pressure in the aquifer or permeability (Kim et al., 2010; Sommer et al., 2013, among others). Yet, it is important to consider more complex injection strategies to correctly evaluate the true stored volume and associated thermal losses, or thermal recovery, in particular in heterogeneous aquifers.

In this study, we investigate the competition between storage capacity and thermal losses for heterogeneous aquifers in the Greater Geneva Basin (GGB), Switzerland. The Canton of Geneva, through the intermediate of the Services Industriels de Geneve (SIG), is currently interested in storing the excess of heat produced by the Cheneviers waste-to-energy plant in the suburban area of Geneva (Quiquerez, 2017; HeatStore). In order to have a full control of the different parameters, we model here only the thermo-hydraulic behaviour of the HT-ATES system, without considering fluid-rock interactions and thermo-mechanical deformation. We investigate the thermal performances (i.e. storage and recovery) under different aquifer properties and injection schedules for the case of the Cheneviers plant, which results in different economical strategies. The aim is to define the conditions in the GGB that maximise the thermal recovery while complying with the local legal regulations and minimising the number of wells to be drilled. This study sets the basis for the ongoing energy storage effort in the GGB (and generally in Switzerland and neighbouring countries) where similar heterogeneous aquifers are found in the North Alpine Foreland basin (PGG, 2011; GeoMolTeam, 2015). Finally, we also introduce a new openaccess, user-friendly and efficient tool to investigate geothermal systems, with a support for complex well strategies.

\section{The Greater Geneva Basin}

\subsection{Geological setting}

The GGB forms the westernmost termination of the North Alpine Foreland Basin (also called Molasse Basin), located between France and Austria, parallel to the Alpine Orogen (Kuhlemann and Kempf, 
2002). The GGB is bounded by the internal chain of the Jura Mountains to the northwest and by the thrusting front of the Alpine units to the southeast (Fig 1a). The Variscan crystalline basement (sensu stricto) of the GGB dips gently to the S-SE $\left(1-3^{\circ}\right)$ and is overlain by a thick (3000-5000 $\mathrm{m}$ ) sedimentary cover of Late Carboniferous to Quaternary deposits (Fig 1b). From the end of the Carboniferous through Permian, SW-NE oriented grabens and relatively small confined basins formed in the basement. They were later filled by continental clastic material, eroded from the Variscan orogen (Wilson et al., 2004; McCann et al., 2006). These sediments and the crystalline basement form the basement sensu lato on which the Triassic deposits unconformably rest (Signer and Gorin, 1995; Sommaruga, 1999). The Lower Triassic (Bundsandstein) is formed of continental sandstones and is overlain by carbonates (Muschelkalk) and evaporites (Keuper) that deposited in a shallow epicontinental sea (Diesler, 1914; Ramsay, 1963; Trümpy, 1980). A rapid phase of marine transgression occurs during the Late Triassic (Rhaetian) and Early Jurassic (Lias). The Lias sediments are mostly composed of bioclastic muddy limestones and dark homogeneous marls that deposited in a distal marine environment (Fig 1b).
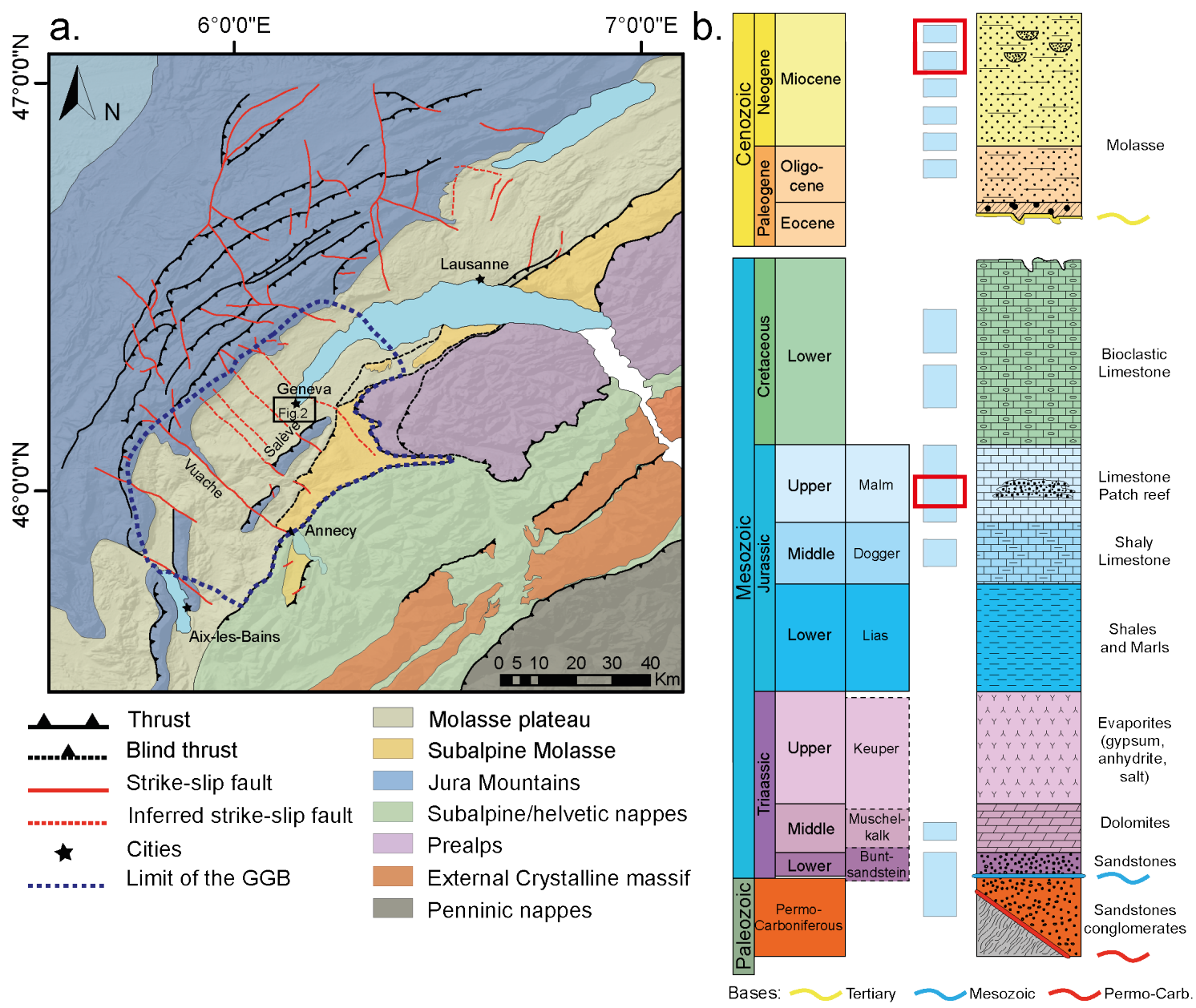

Figure 1: a. Simplified structural map of the Western Alps and Jura Mountains and b. Synthetic log and main aquifers of the Greater Geneva Basin. Red squares: aquifers investigated in this study. Modified after Chelle-Michou et al. (2017) and Chevalier et al. (2010). 
Alternating marls and limestones deposited during the Dogger in a deep marine setting (Choffat, 1878; Conrad, 1969; Blondel, 1990). The Malm is characterised by shallower platform deposits evolving from marly and micritic limestones to biohermal reef facies (e.g. oolithic limestones, coral limestones and lagoonal limestones and calcarenites). The Lower Cretaceous is formed of fine grained bioclastic limestones that deposited in a shallow and warm marine environment (Charollais et al., 2013). During the Late Cretaceous, the GGB came to emersion and the Upper Cretaceous sediments, if deposited, were completely eroded, while the Lower Cretaceous units were largely karstified (Sommaruga, 1997). The warm and subequatorial climate of the Eocene accelerated the erosion of the latter, and the resulting red lateritic deposits filled the karsts and fractures (Becker et al., 2013; Hooker and Weidmann, 2007). The Mesozoic sequence is entirely covered in the basin by Oligocene to Late Miocene alpine sediments (i.e. Molasse) and Quaternary deposits but still outcrops locally in the Jura Mountains, the Mount Salève and the Mount Vuache (Charollais et al., 2007). The Molasse consists of marls and sandstones of marine and continental freshwater environments, whereas the Quaternary formations mostly have a glacial and fluvio-glacial origin (Amberger, 1978; Moscariello et al., 1998). The GGB is affected by two main sets of faults that accomodate the NW-SE alpine compression (Fig 1a). The first set consists of SW-NE thrusts in the Haute-Chaine of the Jura and in the subalpine Molasse, delineating the southeastern rim of the GGB (Fig 1) that are linked with the presence of reactivated Permo-Carboniferous lineaments (Signer and Gorin, 1995). The second set are strike-slip sinistral fault systems, mostly oriented NW-SE (e.g. Vuache fault) that laterally absorb the NW-SE shortening (Fig 1a). At depth, the Keuper evaporites act as a décollement level over which shortening of the Mesozoic and Cenozoic sedimentary cover is accommodated by SW-NE trending folds (Sommaruga, 1999).

Potential aquifers have been recognised in different stratigraphic units of the GGB (Rybach, 1992; Baujard et al., 2007; Chevalier et al., 2010), among which the freshwater Molasse sandstones and Malm patch reef carbonates represent promising targets for the development of ATES systems.

\subsection{The Cheneviers waste-to-energy plant and district heating systems}

District heating systems consist in a network of underground pipes providing heat from a centralised plant, or from a number of distributed smaller heat production units, to a neighbourhood or a city (Fig. 2a). These systems play a key role in increasing the energy efficiency and reducing $\mathrm{CO}_{2}$ emissions, by allowing the utilisation of heat from various sources, such as combined heat and power (CHP), heat from waste-to-energy plants and industrial wastes or geothermal and solar heat (Lund et al., 2014). The Canton of Geneva promotes the development of district heating systems, which currently represent less than $10 \%$ of the heating market (Quiquerez et al., 2016). These infrastructures comprise the large interconnected CADSIG and CADIOM city networks and recent smaller neighbourhood networks (e.g. Cartigny/Aire-la-ville) (Faessler et al., 2015). The CADSIG network, built in the 1960's, was initially 


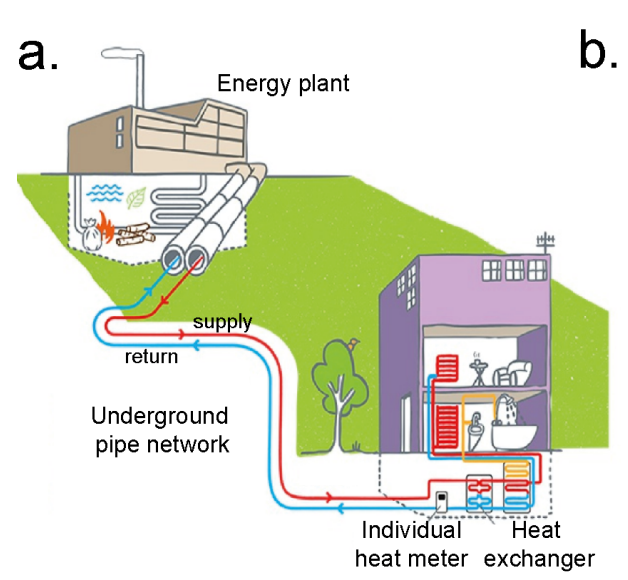
2017).

exclusively powered by gas boilers, whereas the CADIOM network was developed in the early 2000s to recover the heat from the Cheneviers waste-to-energy plant (Fig. 2b). Their interconnection in 2012 allowed the transfer of heat from the CADIOM to CADSIG network and has increased the contribution of waste heat into the network by $77 \mathrm{GWh}$ (Quiquerez et al., 2015). Nevertheless, there is still every summer an excess of 35 GWh from the Cheneviers plant (Fig. 2c) that could be optimised using seasonal ATES solutions (Quiquerez, 2017). This excess of energy is available in the form of a slightly over-pressured, warm liquid water, at temperatures varying between 90 and $120^{\circ} \mathrm{C}$ (Faessler et al., 2015; Quiquerez,
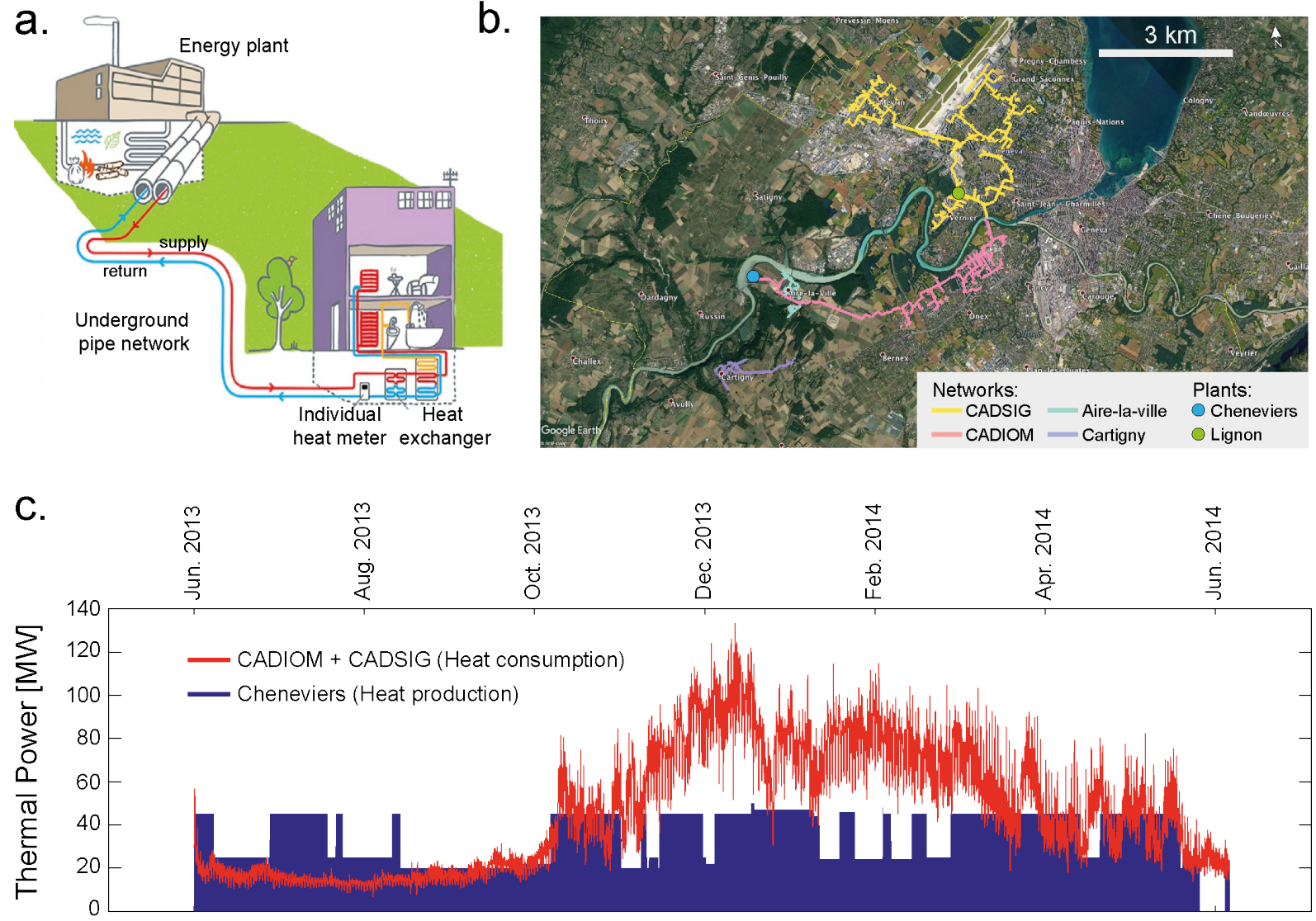

Evolution of heat demands and production from June 2013 to June 2014

Figure 2: a. Schematic drawing showing the principle of a district heating system (source: SIG website, ww2.sig-ge.ch). b. Geographic distribution of the main networks and energy plants for district heating systems in the Geneva Canton. c. Evolution of heat demands from the CADSIG/CADIOM networks and heat production at the Cheneviers plant for the year 2013-2014. Modified after Quiquerez et al. (2016).

In this work, we numerically evaluate the possibility of storing this warm water in either the sandstone channel bars of the Molasse deposits or in the patch-reef carbonates of the Malm units. These two aquifers have very distinctive geometries and properties, and occur at different stratigraphic levels. The shallow $(<1 \mathrm{~km})$ Molasse sandstones have a lateral extension ranging from ten to a few hundred metres 
and show a moderate permeability (up to $1000 \mathrm{mD}$ locally) and high porosity (up to 0.25 ), whereas the deep patch-reef carbonates have a fairly high porosity (0.15) but a low permeability $(1-10 \mathrm{mD})$ (Platt and Keller, 1992; Chevalier et al., 2010; Rusillon, 2017). Rusillon (2017) recently provided a first review of the permeability and porosity measurements from well and outcrop samples in the GGB. The samples were measured in the laboratory using a gas porometer-permeameter. Rusillon (2017) also reported permeability and porosity derived from existing well logs (e.g. hydraulic tests). These measurements revealed a strong lateral and vertical heterogeneity of the rocks with permeability values showing two and four orders of magnitude difference for the Malm and Molasse units, respectively. We therefore perform a parametric study with homogeneous properties for each aquifer type (i.e. Molasse or Malm) that we present in the results. The economical applications and limitations of this study are then discussed, along with additional supporting simulations.

\section{Model}

\subsection{Model presentation}

Numerical simulations of an HT-ATES exploitation can be performed with any groundwater flow modelling software that also considers heat transfers. Among these, COMSOL, ANSYS FLUENT, UTMECH, SEAWAT (MODFLOW family), FEFLOW and TOUGH2 are the most commonly used (Lee, 2010; Dincer and Rosen, 2011). Two aspects are particularly important for simulations of HT-ATES. The first is that a variable density and viscosity should be implemented to capture buoyancy forces, resulting from a density contrast between the injected and the ambient water (Doughty et al., 1982). The second aspect is the possibility of having a mesh refinement around specific parts in the model. This is not mandatory but rather convenient for computing performance, since high spatial resolution is typically only needed near wells. For this study, we use the MATLAB Reservoir Simulation Toolbox (MRST), which is an opensource code compatible with both proprietary (MATLAB) and open source (Octave) software aiming at rapid prototyping of new models and solution strategies for flow in porous media (Krogstad et al., 2015; Lie et al., 2012; Lie, 2019). The toolbox consists of several modules, with support for complex fluid physics and well scheduling, as well as flexible meshing capabilities, but has until now lacked proper support for geothermal simulations. We have developed a new geothermal module in MRST (called geothermal) to investigate heat and mass transport in the GGB. MRST is designed to have the entire workflow within a single framework, from direct import of geophysical and geological data to fluid flow modelling. Moreover, it provides full control over every aspects of the implementation, including fluid and rock properties, well trajectories and injection strategies, as well as numerical considerations such as meshing, discretisations, linear/nonlinear solvers, etc. The support of the existing generic algorithms and their flexibility was a motivation to implement a new geothermal module in MRST. A key distinguishing feature of MRST as a 
prototyping tool is the use of automatic differentiation, where no manual implementation of Jacobians or linearised systems are required. Implementing new governing equations is as simple as implementing the discrete residual with the standard differential operators already implemented in MRST, and Jacobians and a nonlinear solver is automatically defined for the user. As the implementation of Jacobians for new functions can be a time-intensive part of the development process, we believe this greatly improves both prototyping speed and robustness of the resulting simulator.

The newly developed module geothermal implements a non-isothermal single-phase, two-component model for flow in porous media to simulate the injection/production of liquid water in an aquifer. The model equations describe conservation of total fluid mass (i.e. pure water or brine) and concentration of sodium chloride $(\mathrm{NaCl})$, as well as conservation of energy. The two mass-conservation equations read

$$
\begin{aligned}
\frac{\partial}{\partial t}\left(\phi \rho_{f}\right)+\nabla \cdot\left(\rho_{f} \vec{v}\right) & =q_{f}, \\
\frac{\partial}{\partial t}\left(\phi c \rho_{f}\right)+\nabla \cdot\left(c \rho_{f} \vec{v}\right)+\nabla \cdot\left(\phi \tau \rho_{f} D \nabla c\right) & =q_{b},
\end{aligned}
$$

where $\phi$ is the porosity, $\rho_{f}$ the fluid density, $c$ the mass fraction of $\mathrm{NaCl}, \tau$ the tortuosity of the medium and $D$ the $\mathrm{NaCl}$ molecular diffusivity. The Darcy velocity $\vec{v}$ is given from Darcy's law:

$$
\vec{v}=-\frac{1}{\mu_{f}} \mathbf{K}\left(\nabla p-\rho_{f} g \nabla z\right),
$$

where $\mathbf{K}$ is the permeability tensor, $\mu_{f}$ the fluid viscosity, $z$ the depth and $g$ the gravity acceleration. Moreover, $q_{f}$ and $q_{b}$ denote source/sink terms (e.g. wells) for total fluid and $\mathrm{NaCl}$, respectively. Finally, conservation of energy in the system is given by

$$
\frac{\partial}{\partial t}\left((1-\phi) \rho_{r} C_{r} T+\phi \rho_{f} u_{f}\right)+\nabla \cdot\left(\rho_{f} h_{f} \vec{v}\right)-\nabla \cdot \lambda \nabla T=q_{T},
$$

with $\rho_{r}$ and $C_{r}$ the density and heat capacity of the rock, respectively, and $u_{f}$ and $h_{f}$ are the internal energy and enthalpy of the fluid. The temperature is denoted by $T$, and the thermal conductivity $\lambda$ is defined by

$$
\lambda=\phi \lambda_{f}+(1-\phi) \lambda_{r}
$$

where $\lambda_{r}$ and $\lambda_{f}$ are the conductivity of the rock and fluid, respectively. Injected/produced energy is denoted $q_{T}$. The density and viscosity of the fluid are calculated as a function of pressure, temperature and $\mathrm{NaCl}$ concentration using the formulation of Spivey et al. (2004) that has already been implemented in MATLAB (Collignon et al., 2018a,b). This formulation is valid under the ranges of investigated temperature, pressure and $\mathrm{NaCl}$ concentration in our study. Table 1 summarises the parameters used herein. We solve equations (1) - (4) numerically using a fully implicit finite-volume discretisation with two-point flux approximation and single-point upstream mobility weighting. This gives a robust discretisation that is stable over a wide range of timesteps (Lie, 2019; Lie et al., 2012; Krogstad et al., 2015).

A comparison of geothermal with the commercial flow simulator TOUGH2 (Pruess et al., 1999) yields less than $2 \%$ difference in the results. This small discrepancy can be explained by the different implementation 
of fluid properties in both codes (see suppl. mat.). In addition to this benchmark, comparisons with analytical solutions and simple conservative tests have been performed to ensure the correctness of our numerical implementation. Our tests show that geothermal captures the main physical processes at play during HT-ATES exploitation (suppl. mat.).

\begin{tabular}{|c|c|c|c|}
\hline Symbol & Unit & Definition & Value range \\
\hline$x, y, z$ & $\mathrm{~m}$ & coordinates & - \\
\hline$L_{x}, L_{y}, L_{z}$ & $\mathrm{~m}$ & initial dimensions of the model in $x, y$ and $z$ directions & $800,500,310-450$ \\
\hline$h_{\text {top }}$ & $\mathrm{m}$ & top layer thickness & $0-50$ \\
\hline$h_{\mathrm{aq}}$ & $\mathrm{m}$ & aquifer thickness & $10-150$ \\
\hline$d_{\mathrm{aq}}$ & $\mathrm{m}$ & aquifer depth & $150-1500$ \\
\hline$k$ & $\mathrm{mD}$ & aquifer permeability & $0.001-500$ \\
\hline$\phi$ & - & aquifer porosity & $0.01-0.3$ \\
\hline$\vec{v}$ & $\mathrm{~m} \mathrm{~s}^{-1}$ & Darcy velocity & - \\
\hline$v_{\text {aq }}$ & $\mathrm{m} \mathrm{a}^{-1}$ & aquifer flow velocity & $0-50$ \\
\hline$c$ & - & $\mathrm{NaCl}$ mass fraction & $0.002-0.06$ \\
\hline$C_{r}$ & $\mathrm{~J} \mathrm{~kg}^{-1} \mathrm{~K}^{-1}$ & rock heat capacity & 2300 \\
\hline$C_{f}$ & $\mathrm{~J} \mathrm{~kg}^{-1} \mathrm{~K}^{-1}$ & fluid heat capacity & 4200 \\
\hline$C_{\text {aq }}$ & $\mathrm{J} \mathrm{kg}^{-1} \mathrm{~K}^{-1}$ & aquifer heat capacity & - \\
\hline$\lambda_{r}$ & $\mathrm{~W} \mathrm{~m} \mathrm{~m}^{-1} \mathrm{~K}^{-1}$ & rock thermal conductivity & 1.8 \\
\hline$\lambda_{f}$ & $\mathrm{~W} \mathrm{~m} \mathrm{~m}^{-1} \mathrm{~K}^{-1}$ & fluid thermal conductivity & 0.6 \\
\hline$\lambda_{\mathrm{aq}}$ & $\mathrm{W} \mathrm{m}^{-1} \mathrm{~K}^{-1}$ & aquifer thermal conductivity & - \\
\hline$\rho_{r}$ & $\mathrm{~kg} \mathrm{~m}^{-3}$ & rock density & 2500 \\
\hline$D$ & $\mathrm{~m}^{2} \mathrm{~s}^{-1}$ & $\mathrm{NaCl}$ molecular diffusivity & $10^{-6}$ \\
\hline$\tau$ & - & medium tortuosity & 1 \\
\hline$\mu_{f}$ & $\mathrm{~Pa} \mathrm{~s}$ & fluid viscosity & - \\
\hline$\rho_{f}$ & $\mathrm{~kg} \mathrm{~m}^{-3}$ & fluid density & - \\
\hline$V_{f}$ & $\mathrm{~m}^{3}$ & injected fluid volume & - \\
\hline$E$ & $\mathrm{~J}$ & energy & - \\
\hline$P$ & $\mathrm{~W}$ & thermal power & - \\
\hline$\eta$ & - & energy recovery factor & - \\
\hline$T_{\text {cold }}$ & ${ }^{\circ} \mathrm{C}$ & temperature of injected water at the cold well & $12.61-49.9$ \\
\hline$T_{\text {warm }}$ & ${ }^{\circ} \mathrm{C}$ & temperature of injected water at the warm well & $60-120$ \\
\hline$T_{\lim }$ & ${ }^{\circ} \mathrm{C}$ & cut-off temperature for the unloading phase & none -100 \\
\hline bhpmin & bar & minimum well pressure & 1 \\
\hline bhpmax & bar & maximum well pressure & $75-250$ \\
\hline$Q_{\text {inj }}$ & $\mathrm{L} \mathrm{s}^{-1}$ & injection rate & $5-20$ \\
\hline$Q_{\text {prod }}$ & $\mathrm{L} \mathrm{s}^{-1}$ & production rate & $5-20$ \\
\hline
\end{tabular}

Table 1: Physical parameters for the study. Only the values (or range) of input parameters are reported in the $4^{\text {th }}$ column. Values (or range) calculated by the model such as density, viscosity, pressure and temperature are not reported here. 


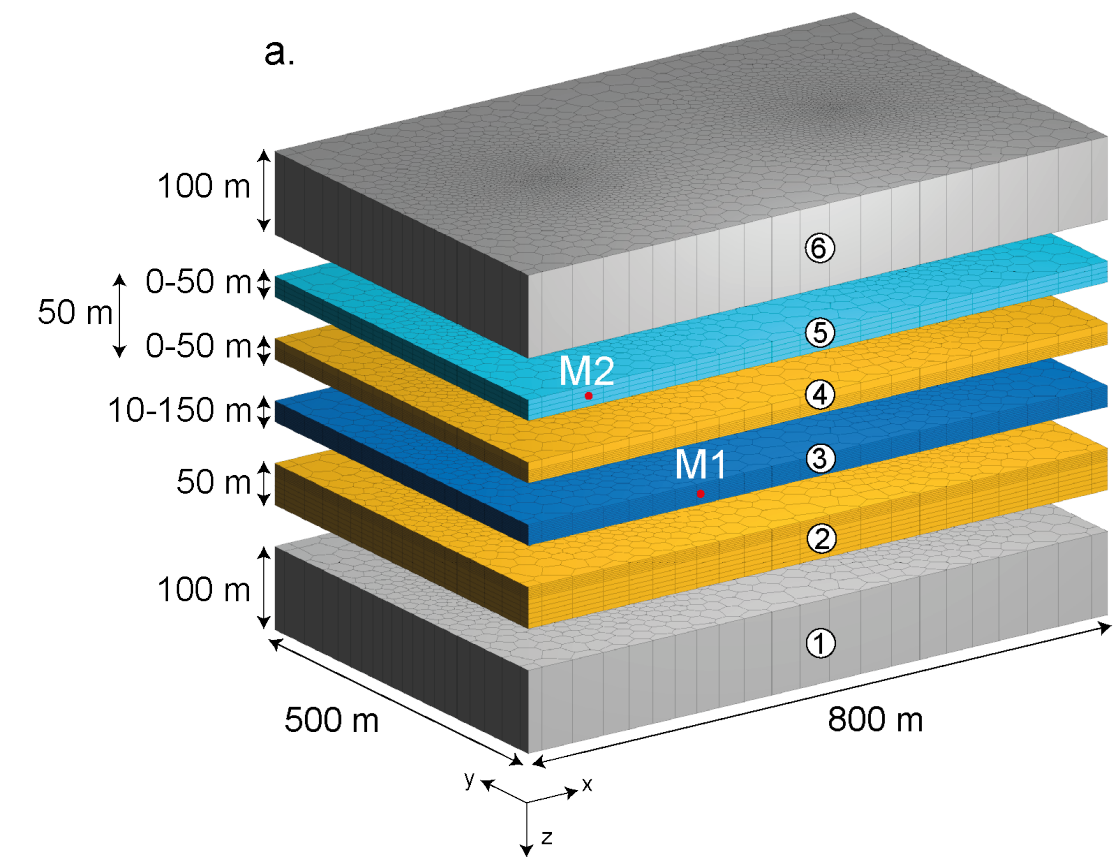
(Fig. 3a)

\subsection{Geometry, boundary conditions and key assumptions}

Our aim is to understand the primary control of rock properties and aquifer flow conditions on the thermal performance and environmental impact of a HT-ATES system. Therefore, we employ a simple model geometry as more complex geological surfaces could induce preferential flow directions that would bias the interpretation of the parameter controls. The generic model consists in a 3D block with a lateral area of $800 \times 500 \mathrm{~m}^{2}$, and a vertical thickness that varies between 310 and $450 \mathrm{~m}$ for different configurations

Figure 3: a. Side-view of the generic model (decomposed) with layer dimensions. Not to scale. Grey: low permeable pad layers (1 and 6), dark blue: storage aquifer (3), light blue: drinking water aquifer (5), yellow: low-permeability rock layers (2 and 4$)$. b. Top view of the aquifer with well location and mesh resolution. M1-M2: monitoring points used to evaluate the HT-ATES environmental impact, projected on the front side of the model (see Fig. 9).

The model is divided into different layers (1-6 in Fig. 3a) with from bottom to top: a $100 \mathrm{~m}$ low permeable padding layer (1), a $50 \mathrm{~m}$ low permeable rock (2), a 10-50 m storage aquifer (3), a 0-50 m low permeable rock (4), a 0-50 m shallower aquifer (5) and a $100 \mathrm{~m}$ low permeable padding layer (6). Layers 4 and 5 always have a total thickness of $50 \mathrm{~m}$ (Fig. 3). In addition to the thickness of the storage aquifer (3), we also vary the thickness of its upper low-permeability unit (4) to investigate the effect of heat storage on an overlying aquifer of drinking water (5). Such a configuration can be found in the GGB, with drinking water aquifers occurring in Quaternary deposits (GeoMolTeam, 2015). The padding layers $(1,6)$ are used to prescribe boundary conditions away from the aquifer, so that they reflect a basin equilibrium state and do not perturb the flow field induced by injection and extraction of water at the wells.

We generate the unstructured grid with the upr module (Berge et al., 2018) to allow a mesh refinement 
around specific areas inside the model (e.g. wells, aquifers, aquifer-rock interfaces), where pressure and temperature variations can be sharp. The mesh is radially refined around the wells, with a finest horizontal resolution of $2 \mathrm{~m}$ (Fig. 3b). The storage aquifer (3) has a vertical resolution of $2 \mathrm{~m}$. The low-permeability rock units $(2,4)$ and/or shallower aquifer (5) have a vertical resolution of $2 \mathrm{~m}$ in the first $30 \mathrm{~m}$, near the aquifer, and of $5 \mathrm{~m}$ for the rest of these units. Finally, the padding layers $(1,6)$ only have two elements in the vertical direction (Fig. 3a). Additional tests (not reported here) have shown that this resolution is sufficient as mass and heat transfers in this part of the model are negligible.

We consider an HT-ATES system with a pair of wells, called "warm" and "cold", that operate in an opposite mode. When the cold well is injecting, the warm well is producing and vice-versa. Similar to LT-ATES systems used in heating/cooling of buildings, each well operates successively in injection and production modes, depending of the season. We therefore refer to warm/cold rather than injection/production wells, as warm (or cold) water is always injected (or produced) at the same well. The thermal radius $\left(R_{\mathrm{th}}\right)$ of an ATES well corresponds to the maximum distance from the injection well reached by the thermal front in a homogeneous medium (Sommer et al., 2015; Bloemendal et al., 2018). It serves as an initial estimate of the thermally affected area around the well and is defined as

$$
R_{\mathrm{th}}=\sqrt{\frac{C_{f} V_{f}}{C_{\mathrm{aq}} \pi h_{\mathrm{aq}}}},
$$

where $C_{\mathrm{aq}}$ and $C_{f}$ are the aquifer and fluid heat capacity, respectively, $V_{f}$ the volume of injected fluid, and $h_{\mathrm{aq}}$ the aquifer thickness. To do a clean-cut comparison between the different investigated configurations, we keep a constant distance between the wells in all simulations. This distance is $400 \mathrm{~m}$ and corresponds to twice the maximum estimated thermal radius, as recommended by Sommer et al. (2013) to limit thermal interference. This maximal thermal radius is estimated for the simulation with the minimal aquifer thickness and maximal injected volume.

We assume an initial quasi-hydrostatic pressure gradient in the entire model (defined as $p_{0}=\rho g z$, with $\rho=1000 \mathrm{~kg} \mathrm{~m}^{-3}$ ). The temperature gradient in the GGB varies with depth (Chelle-Michou et al., 2017). Accordingly, we prescribe a temperature gradient of 17.4 and $26.6^{\circ} \mathrm{C} / \mathrm{km}$ for the Molasse and Malm aquifers, respectively, and a surface temperature of $10^{\circ} \mathrm{C}$. Equilibrium pressure and temperature conditions (similar to initial gradients) are imposed at all boundaries. We specify a flux boundary condition on the back-side of the model (faces parallel to the $x$-axis, at $\mathrm{y}=500 \mathrm{~m}$ ) when investigating the effects of the aquifer flow velocity. This boundary condition is only assigned to the back-side faces of the storage aquifer (layer 3, Fig. 3).

The estimated lifetime of an ATES system ranges from 25 to 50 years (Hartog et al., 2013; Bloemendal et al., 2014) and its payback time (i.e. time before it is economically viable) typically varies between 2 and 10 years, but can be up to 15 years (Fleuchaus et al., 2018). To ensure that we reach the payback time and the maximum thermal recovery in our study, we simulate the HT-ATES exploitation for 20 years, which 
corresponds to 20 repeating cycles. We use the same exploitation schedule for the wells in all simulations. A cycle is divided into an equal loading and unloading phase of four months, separated by two months of rest. The loading phase corresponds to the storage of warm water in the aquifer (from May to August, Fig. 2c), whereas the unloading phase is its withdrawal from the aquifer (from November to February). No water is neither injected nor extracted during the resting phases. In the following parametric study, we set the temperature of the injected water at the warm well to $90^{\circ} \mathrm{C}$, which corresponds to the supply temperature of the CADSIG/CADIOM networks during summer (Faessler et al., 2015; Quiquerez et al., 2015). The temperature of the injected water at the cold well varies between 12.6 and $49.9^{\circ} \mathrm{C}$, depending on the model configuration, and is equivalent to the initial temperature at the top of the aquifer. Injection and production rates are set identical to keep a pressure balance in the aquifer and to ensure that the volume of injected or pumped water complies with legal recommendations (CH-GSchV, 1998; OFEV, 2009). The rates vary between 5 and $20 \mathrm{~L} \mathrm{~s}^{-1}$, depending on the aquifer permeability and depth. Lower and upper limits of the bottom hole pressure (bhp) at the wells are imposed to ensure that the pressure does not drop below unrealistic values $(<1$ bar) or does not exceed a failure criteria (e.g. lithostatic pressure). A cut-off based on temperature can also be used during the unloading phase depending on the desired application of the stored energy: once the temperature drops below this cut-off limit, both wells stop injecting and producing and the remaining time of the unloading phase becomes a resting phase.

\subsection{Choice of aquifers and well parameters}

Although many studies focus on the GGB, some physical parameters such as the aquifer flow velocity and salinity, as well as the thermal rock properties remain poorly constrained (Rusillon, 2017; GeoMolTeam, 2015). Permeability and porosity measurements reveal a strong heterogeneity within the same rock units and would require more systematic sampling and analysis to provide a detailed and realistic distribution of the rock petrophysical properties (Rusillon, 2017; Makhloufi et al., 2018). We instead define two reference models that represent a typical average aquifer for the Molasse and Malm units, referred as Molasse0 and Malm0, respectively (Table 2). We only consider sandstone beds as a potential aquifer for the Molasse, and therefore marls and silstones are disregarded when evaluating the permeability and porosity of the Molasse aquifers. The aquifer flow velocity and salinity have been set to zero for the reference models. Molasse0 has a $25 \mathrm{~m}$ thick aquifer, whose top is set at $250 \mathrm{~m}$ depth. The aquifer permeability and porosity are $200 \mathrm{mD}$ and 0.20 , respectively (Table 2). The aquifer of Malm0 is $100 \mathrm{~m}$ thick, with its top at $1100 \mathrm{~m}$ depth, has a permeability of $10 \mathrm{mD}$ and a porosity of 0.15 (Table 2). 


\begin{tabular}{lcccccccccccccc}
\hline Simulation & $\begin{array}{c}h_{\mathrm{top}} \\
\mathrm{m}\end{array}$ & $\begin{array}{c}h_{\mathrm{aq}} \\
\mathrm{m}\end{array}$ & $\begin{array}{c}d_{\mathrm{aq}} \\
\mathrm{m}\end{array}$ & $\begin{array}{c}k \\
\mathrm{mD}\end{array}$ & $\begin{array}{c}\phi \\
-\end{array}$ & $\begin{array}{c}v_{\mathrm{aq}} \\
\mathrm{m} \mathrm{a}^{-1}\end{array}$ & $\begin{array}{c}c \\
-\end{array}$ & $\begin{array}{c}Q_{\mathrm{inj}} \\
\mathrm{L} \mathrm{s}^{-1}\end{array}$ & $\begin{array}{c}T_{\mathrm{warm}}{ }^{*} \mathrm{C} \\
{ }^{\circ}\end{array}$ & $\begin{array}{c}T_{\text {cold }} \\
{ }^{\circ} \mathrm{C}\end{array}$ & $\begin{array}{c}\mathrm{bhp}_{\min }{ }^{*} \\
\text { bar }\end{array}$ & $\begin{array}{c}\mathrm{bhp}_{\max }^{*} \\
\text { bar }\end{array}$ & $\begin{array}{c}T_{\text {lim }}{ }^{*} \\
{ }^{\circ} \mathrm{C}\end{array}$ \\
\hline \hline Molasse0 & 50 & 25 & 250 & 200 & 0.2 & 0 & 0 & 15 & 90 & 14.35 & 1 & 75 & none \\
\hline Malm0 & 50 & 100 & 1100 & 10 & 0.15 & 0 & 0 & 10 & 90 & 39.26 & 1 & 250 & none \\
\hline
\end{tabular}

Table 2: Physical parameters for Molasse0 and Malm0. *: fixed parameters in all simulations of the parametric study.

The investigated values in the parametric study for the aquifer thickness, depth, permeability and porosity (Tables 1-2) represent the lower and upper bounds of averaged Malm carbonate or Molasse sandstone aquifers (Brentini, 2018; Rusillon, 2017). The investigated values for the aquifer flow velocity are close to and above the critical velocity value for heat storage $\left(18 \mathrm{~m} \mathrm{a}^{-1}\right)$, estimated by Courtois et al. (2006). No data for the flow direction and velocity are available for the Malm aquifers, whereas the discharge rate measurements (from drilled wells) in the Molasse units are too scarce to conclude on a realistic value of the aquifer flow velocity. Water salinity range from 0.3 to $40 \mathrm{~g} \mathrm{~L}^{-1}$ in the Malm units (Rusillon, 2017). Only one sample was measured for the Molasse deposits and gave a salinity lower than $1 \mathrm{~g} \mathrm{~L}^{-1}$ (GeoMolTeam, 2015). These values are typical for sedimentary basins and generally too low to strongly affect the water density or viscosity (Spivey et al., 2004). Major thrusts in the basement cross-cut the entire sedimentary cover and have been suggested to be a path for migration of deep and warm fluids from the basement to shallower units (Chelle-Michou et al., 2017). These thrusts could potentially drive high-salinity fluids from the Keuper evaporites, resulting in local high-salinity regions where the concentration is higher than the measured values. Therefore, we present here simulations with salinity higher than the maximum measured values that could potentially affect the HT-ATES performance. Additional simulations with salinity in the range of those measured in the GGB (not reported here) show no significant effects on the HT-ATES performance compared to freshwater simulations.

The low permeable rock and padding layers (1,2,4,6, Fig. 3a) have an extremely low porosity (0.01) and permeability $(0.001 \mathrm{mD})$ in all simulations to ensure that negligible flow occurs in these parts of the model. The drinking water aquifer (5, Fig. 3a), when considered, has the same permeability and porosity as the storage aquifer. The upper low-permeability layer (3, Fig. 3a) has a thickness of $50 \mathrm{~m}$ for the reference models and vary between 0 and $50 \mathrm{~m}$ in other configurations. The thermal properties of rocks in the GGB are poorly constrained. We thus use a typical average heat capacity and thermal conductivity (Table 1) for sedimentary rocks (Kappelmeyer and Haenel, 1974). The water heat capacity and thermal conductivity show negligible changes for the investigated temperature, pressure and salinity ranges (Driesner, 2007). Thermal parameters are kept constant in all simulations (Table 1). We impose an upper bhp limit at 75 and 250 bars for the investigated Molasse and the Malm aquifers, respectively, during the loading and unloading phases. These limits correspond in average to the estimated lithostatic pressures at the top of the aquifer. The injection and production rates are scaled with the aquifer depth 
and permeability, so that the bhp limit is not reached too rapidly in the simulations. The rates are set to 5,15 and $20 \mathrm{~L} \mathrm{~s}^{-1}$ for permeabilities of 10,200 and $500 \mathrm{mD}$, respectively, for the Molasse aquifers. They are set to 5,10 and $15 \mathrm{~L} \mathrm{~s}^{-1}$ for permeabilities of 2, 10 and $50 \mathrm{mD}$ respectively, for the Malm aquifers.

\section{Results of the parametric study}

Fourteen simulations, including the reference model, were performed for each aquifer type. We successively investigate the effects of the aquifer geometry (depth and thickness) and properties (permeability, porosity, flow velocity and salinity), as well as the thickness of the upper low-permeability layer. In each simulation, only one of these parameters varies to evaluate its effect on the HT-ATES performance and environmental impact.

\subsection{Reference models}

When injecting warm water into a colder aquifer, a thermal perturbation forms at the well and progressively radially expands inside the aquifer. The maximal distance reached by this perturbation front (or thermal radius) mostly depends on the aquifer thickness, the volume of injected water and the temperature contrast between this water and the aquifer (Fig. 4). To compare the thermally affected area in the different simulations, we define as the heat plume the region of the aquifer where the temperature is at least 30\% higher than the average aquifer temperature. This $30 \%$ increase ensures that we only capture the thermal perturbation due to heat storage and not the temperature variations at the top or bottom of the aquifer, that can show up to $25 \%$ deviation from the averaged temperatures depending on the model configuration and prescribed thermal gradient. The radius of this heat plume is referred to $R_{\mathrm{th}, 30}$ to distinguish from the true thermal radius $R_{\mathrm{th}}$.

A larger volume of warm water is injected into a thinner aquifer for Molasse0 than for Malm0, which results in a wider heat plume. At the beginning of the unloading phase of the $10^{\text {th }} \mathrm{cycle}, R_{\mathrm{th}, 30}$ is equal to $102 \mathrm{~m}$ for Molasse0 and to $34 \mathrm{~m}$ for Malm0 (Fig. 4). For both models, $R_{\mathrm{th}, 30}$ is only reduced by approximately $10 \%$ at the end of the unloading phase. The contact surface between the aquifer and the low-permeability rocks is larger for Molasse0 than for Malm0, which leads to a higher thermal perturbation into the low-permeability rock units (Fig. 4). As only a part of the injected heat is recovered at each cycle, the heat plume is expected to grow further away from the well and the aquifer will overall warm up with time. The temperature at the warm well generally increases with time but strongly fluctuates during the loading and unloading phases (Fig. 5a). Smooth temperature variations also occur during the resting phases. The temperature variations in the warm well show larger amplitudes for Molasse0 than for Malm0 because the temperature contrast between the injected water and the aquifer is larger. 
Molasse0

a.
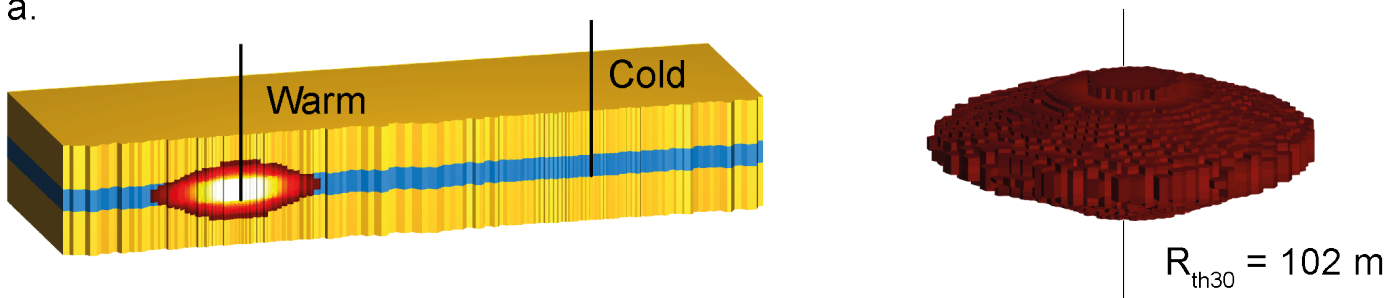

b.
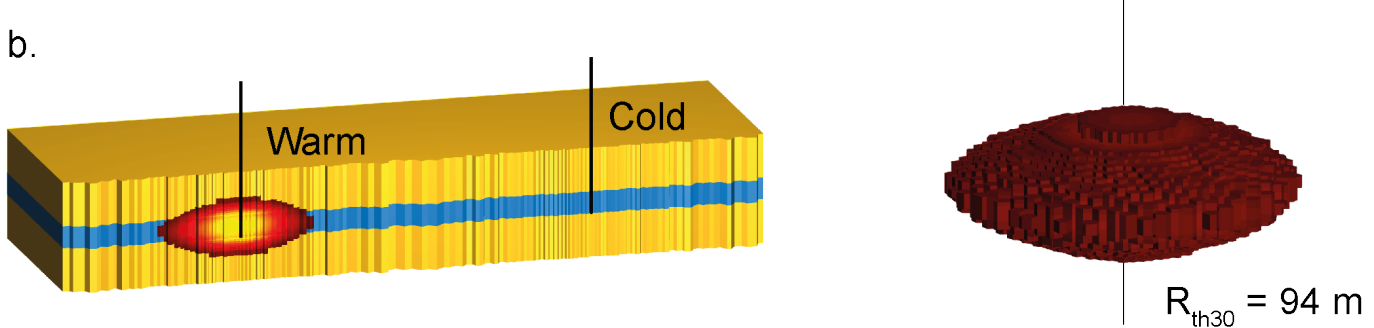

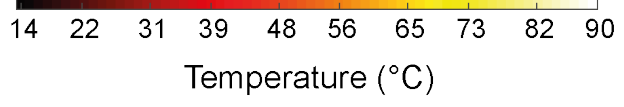

\section{Malmo}

c.
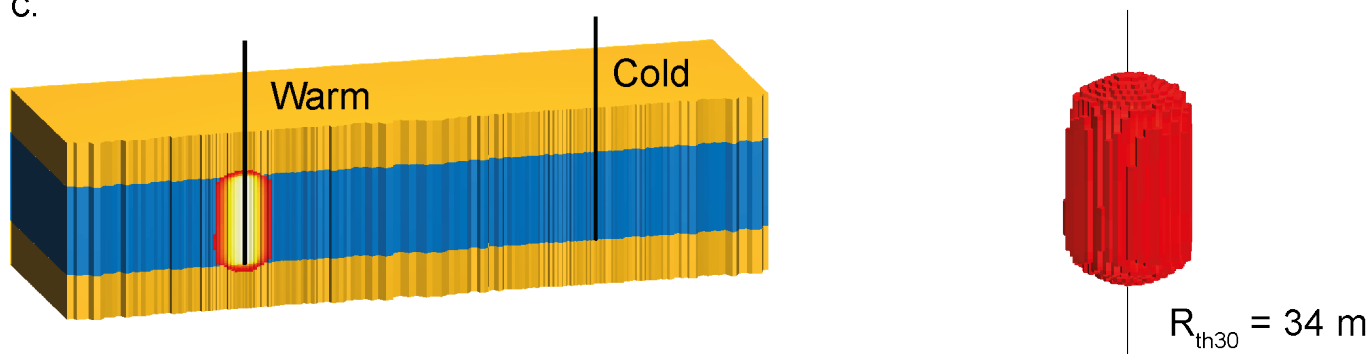

d.
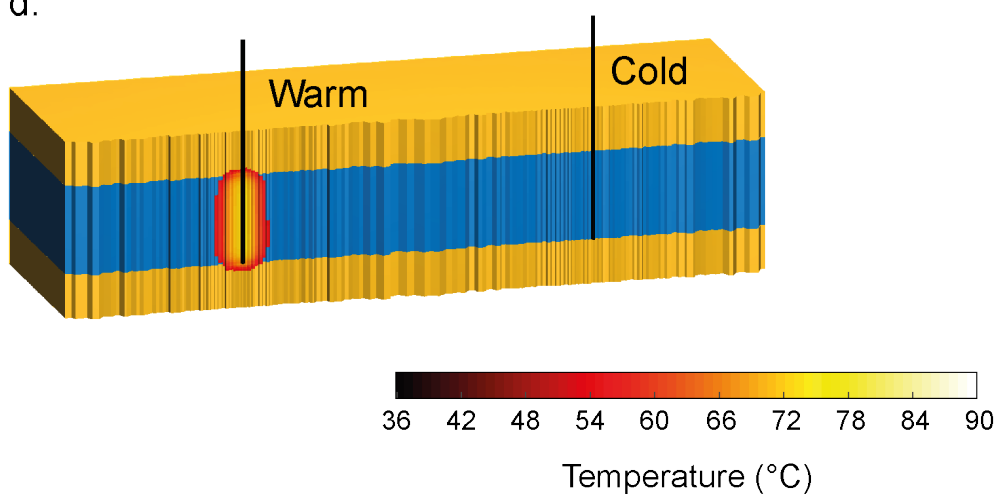

$$
\mathrm{R}_{\mathrm{th} 30}=31 \mathrm{~m}
$$

Figure 4: Left: Vertical cross-sections of Molasse0 and Malm0 at the beginning $(\mathbf{a}, \mathbf{c})$ and end (b,d) of the unloading phase for the $10^{\text {th }}$ cycle. Right: Extracted corresponding heat plume defined as a $30 \%$ increase of the initial average temperature in the aquifer $\left(\mathrm{R}_{t h 30}\right)$. 
For Molasse0, the temperature at the warm well fluctuates between 48 and $90^{\circ} \mathrm{C}$ at the beginning of the HT-ATES exploitation and between 70 and $90^{\circ} \mathrm{C}$ towards the end. For Malm0, it varies between 60 and $90^{\circ} \mathrm{C}$ during the first year, but does not drop below $77^{\circ} \mathrm{C}$ during the last five years of simulation (Fig. 5a). The temperature at the cold well overall decreases with time because the injected water is slightly colder than the aquifer average temperature. Temperature variations in the cold well are very small for both aquifers $\left(\max .2 .65{ }^{\circ} \mathrm{C}\right)$ and negligible compared to those at the warm well $\left(\min .12^{\circ} \mathrm{C}\right)$ (Fig. 5b,c).

\subsection{Energy stock}

Fig. 6 reports the range of values for $R_{\mathrm{th}, 30}$ during the entire HT-ATES exploitation for all simulations. $R_{\mathrm{th}, 30}$ shows greater variations for the Molasse than for the Malm aquifers because they are generally thinner and the volume of injected water larger. The main parameters controlling $R_{\mathrm{th}, 30}$ are the thickness, depth, permeability and flow velocity of the aquifer. The absence of an upper low-permeability layer plays a role in the case of a $25 \mathrm{~m}$ thick aquifer with a large volume of injected water (Fig. 6a). However, it has almost no effect for a $100 \mathrm{~m}$ thick aquifer with a small to moderate volume of injected water (Fig. $6 \mathrm{~b})$. The aquifer porosity and salinity have little to no effects on $R_{\mathrm{th}, 30}$. For the Molasse aquifers, $R_{\mathrm{th}, 30}$ varies between $\sim 50$ and $\sim 120$ m during the HT-ATES exploitation for Molasse0 but decreases to $\sim 20$ $\mathrm{m}$ for a low permeability aquifer $(10 \mathrm{mD})$ and increases up to $\sim 200 \mathrm{~m}$ for a very thin $(10 \mathrm{~m})$ aquifer (Fig. 6a). Variations of $R_{\mathrm{th}, 30}$ during the HT-ATES exploitation are also the smallest and the largest for the low permeability and thin aquifers, respectively. For the Malm aquifers, $R_{\mathrm{th}, 30}$ ranges from $\sim 10$ to $\sim 40 \mathrm{~m}$ during the HT-ATES exploitation for Malm0 (Fig. 6b), but can reach almost $80 \mathrm{~m}$ for aquifers with a high flow velocity $\left(>50 \mathrm{~m} \mathrm{a}^{-1}\right)$. For deep aquifers $\left(d_{\mathrm{aq}}=1500 \mathrm{~m}\right)$, the thermal plume may even disappear after an unloading phase, as the temperature contrast between the injected water and the aquifer decreases. Smallest and largest variations of $R_{\mathrm{th}, 30}$ during the HT-ATES exploitation are observed for the thickest aquifer and the aquifer with the highest flow velocity, respectively (Fig. 6b).

\subsection{Thermal performance}

We also evaluate the thermal performance of the HT-ATES in terms of storage capacity and thermal recovery. The storage capacity is defined as the maximum stored energy per cycle, which is primarily controlled by the injection rate. This latter is a function of the aquifer permeability and depth, and the imposed bhp limit. For the Molasse aquifers, the storage capacity per cycle is $\sim 50 \mathrm{TJ}$ on average. It reaches almost $75 \mathrm{TJ}$ for an aquifer with a $500 \mathrm{mD}$ permeability but drops below $10 \mathrm{TJ}$ when the aquifer permeability is around $10 \mathrm{mD}$ (Fig. 7a). For the Malm aquifers, the storage capacity is less than half of that observed for the Molasse aquifers, with nearly $20 \mathrm{TJ}$ on average. It drops to $10 \mathrm{TJ}$ for an aquifer 

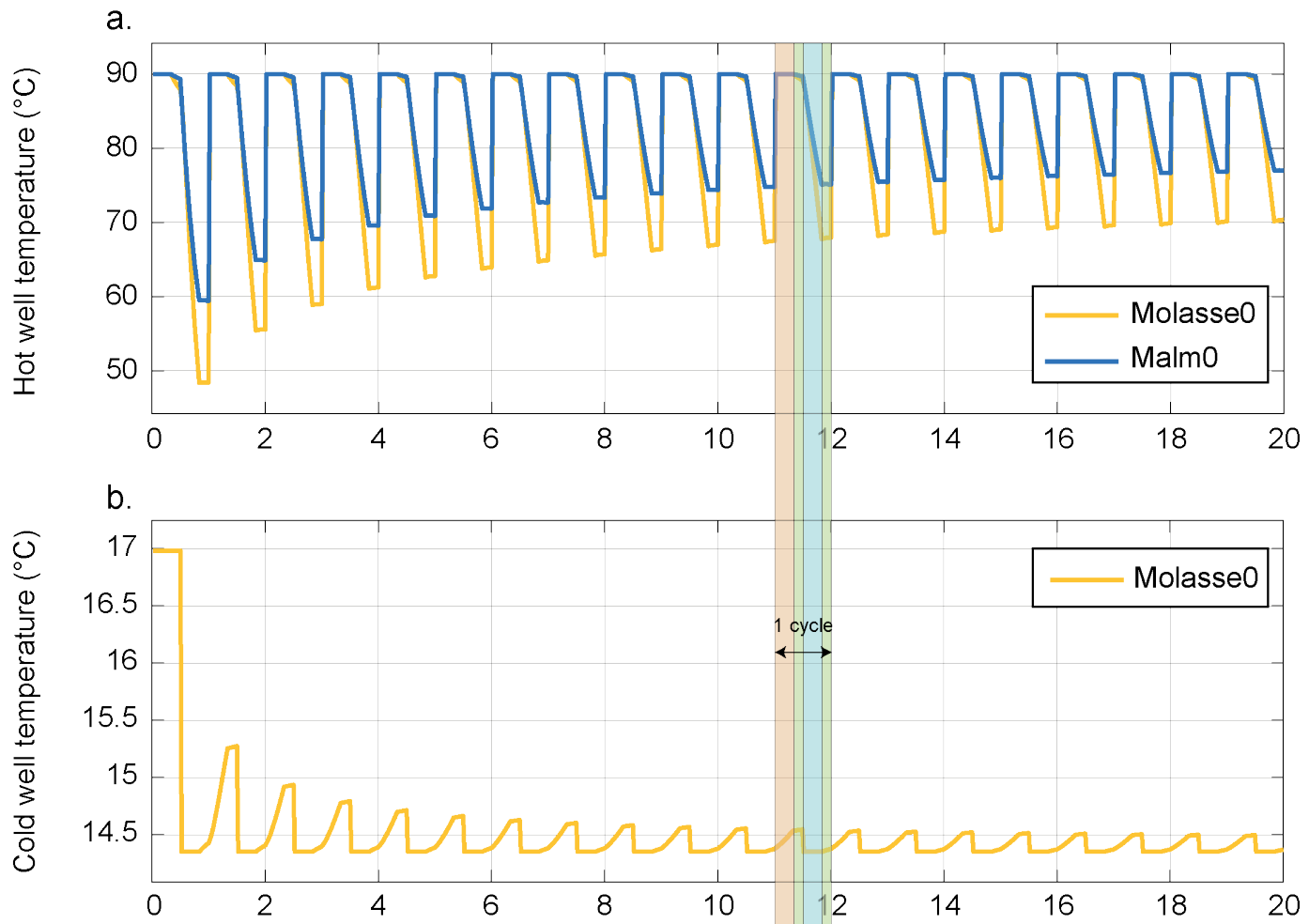

c.

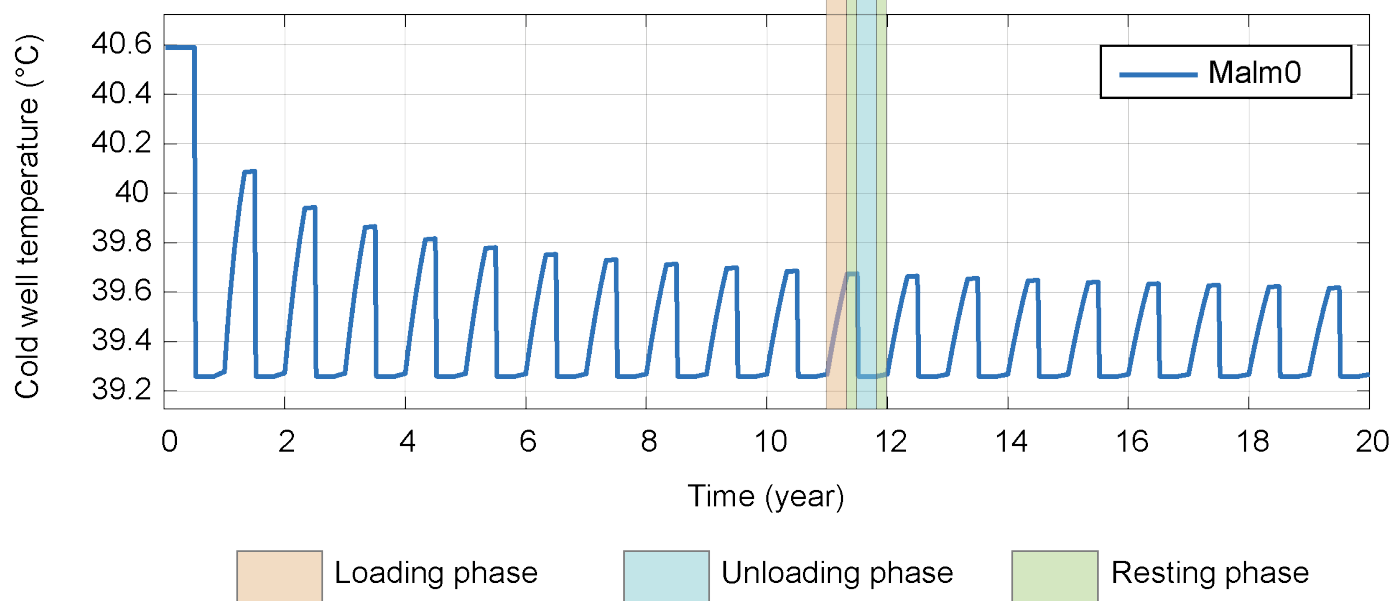

Figure 5: Temporal evolution of the temperature at the warm (a.) and cold (b,c.) wells for both reference models. 


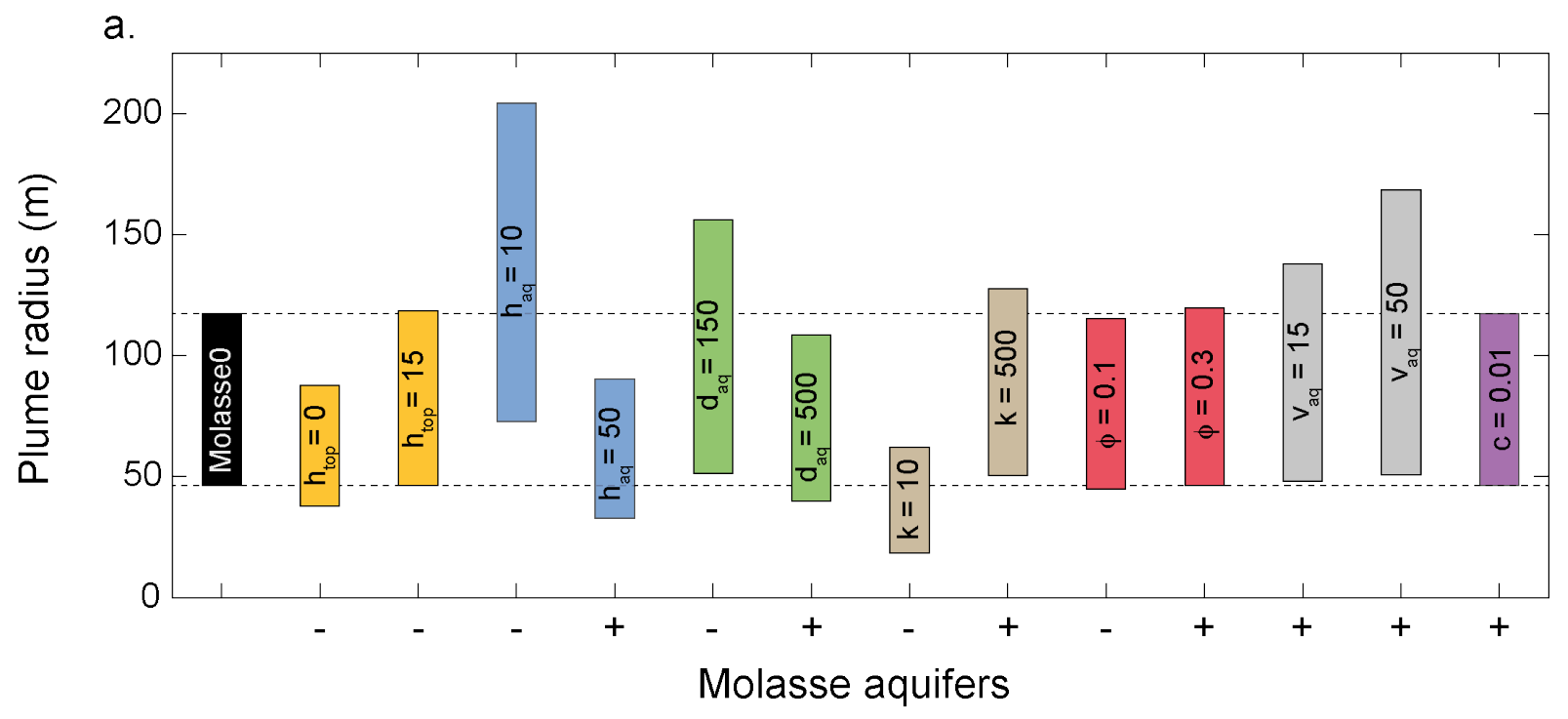

b.

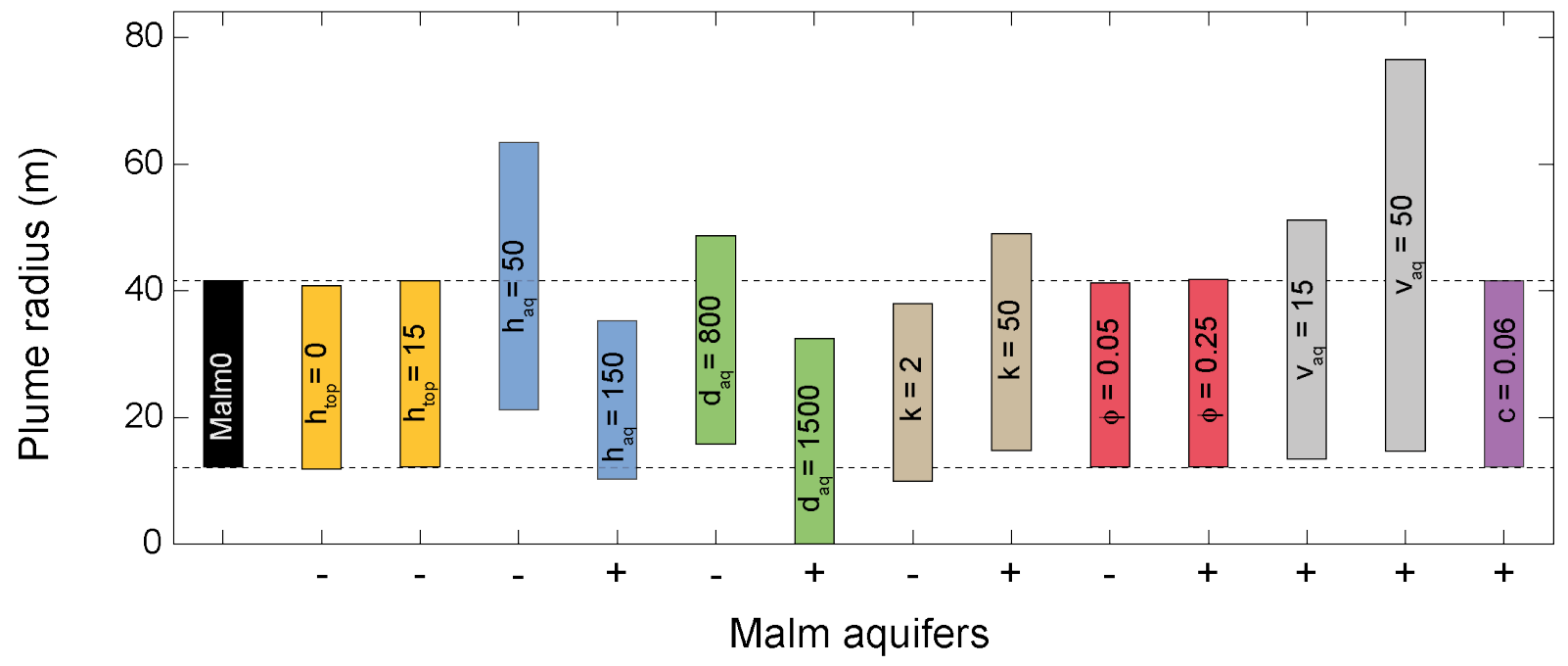

Figure 6: Variations of the heat plume radius $\left(\mathrm{R}_{t h 30}\right)$ during the HT-ATES exploitation for the different Molasse (a.) and Malm (b.) aquifers. The bars represent the range of values of the plume radius during the HT-ATES simulation. Each colour corresponds to an investigated parameter. Black: reference model, yellow: thickness of the upper low-permeability layer, blue: aquifer thickness, green: aquifer depth, brown: aquifer permeability, pink: porosity, grey: aquifer flow velocity and purple: aquifer salinity. Investigated parameters are given in the figure for each simulation, with a plus or minus sign to indicate if the simulated value is higher $(+)$ or lower $(-)$ than the corresponding value in the reference model. Units and other constant parameters are given in Tables 1-2. 
permeability around $2 \mathrm{mD}$ and reaches almost 35 TJ for an aquifer with a $50 \mathrm{mD}$ permeability (Fig. 7b). Although the imposed injection/production rates and aquifer permeabilities are identical, smaller variations in the storage capacity are observed for aquifers with different thicknesses and depths than the reference models (Fig. 7a,b). This can be explained by the use of fixed bhp limits. When changing the aquifer depth or thickness, the water pressure in the wells may deviate significantly from the well pressure in the reference models and may reach the bhp limit at a different time of the simulated loading/unloading phase. This results in different volumes of injected water and thus of stored energy.

The thermal recovery is evaluated through the non-dimensional energy recovery factor, $\eta$, which is defined as the ratio of the produced to the injected energy during each cycle:

$$
\eta=\frac{E_{\text {prod }}}{E_{\text {inj }}}=\frac{\int_{0}^{t_{\text {prod }}} P_{\text {prod }}(t) \mathrm{d} t}{\int_{0}^{t_{\text {inj }}} P_{\text {inj }}(t) \mathrm{d} t},
$$

with $P_{\text {inj }}$ and $P_{\text {prod }}$, the thermal power at the loading or unloading phase, respectively, of each cycle, which is defined as:

$$
P_{\text {prod }}(t)=\rho_{f} C_{f} Q_{\mathrm{prod}}(t)\left|T_{\mathrm{prod}}(t)-T_{\mathrm{aq}}^{0}\right| \quad \text { and } \quad P_{\mathrm{inj}}(t)=\rho_{f} C_{f} Q_{\mathrm{inj}}(t)\left|T_{\mathrm{inj}}(t)-T_{\mathrm{aq}}^{0}\right|
$$

with $Q_{\mathrm{prod}}$ and $Q_{\mathrm{inj}}$ the production and injection rates measured at the warm well and $T_{\mathrm{aq}}^{0}$ the aquifer temperature at the beginning of the loading/unloading phases.

No cut-off temperature is imposed during the unloading phases. This ensures that the produced volume of warm water is similar to the one injected during the loading phase, effectively limiting the overall temperature increase in the aquifer. However, a cut-off temperature is used in the post-processing when calculating $\eta$. Here, we aim at evaluating the thermal recovery for a specific application, namely, directly re-injecting the warm water into the pipe network of one of the district heating systems near Geneva to provide heat to buildings. Currently, the supply temperature of the CADSIG and CADIOM networks is around $100-110^{\circ} \mathrm{C}$ in winter but could drop to $70-80^{\circ} \mathrm{C}$ with an optimisation of the network temperatures (Faessler et al., 2015). This latter temperature range corresponds to the supply temperature of the Cartigny and Aire-la-ville networks in winter and is also more typical for third generation district heating (3GDH) systems (Lund et al., 2018). We thus evaluate the thermal recovery with a cut-off temperature at $80^{\circ} \mathrm{C}$. The excess of produced energy (for $\mathrm{T}<80^{\circ} \mathrm{C}$ ) is here considered wasted.

The energy recovery factor improves with time as the temperature contrast between the injected water and the aquifer decreases. For most of the investigated aquifers, $\eta$ rapidly increases in the first years and reaches its maximum before 15 years (Fig. 8). The energy recovery factor is usually smaller than 0.2 for the first year (with the exception of two Malm aquifers) and does not exceed 0.4 after five years (Fig. 8). After 20 years, $\eta$ varies between 0.24 and 0.54 for the Molasse aquifers and between 0.23 and 0.79 for the Malm aquifers (Fig. 8). The lowest energy recovery factor is observed for the Malm aquifer with a flow velocity of $50 \mathrm{~m} \mathrm{a}^{-1}$, where $\eta=0.23$ after 20 years. 
a.

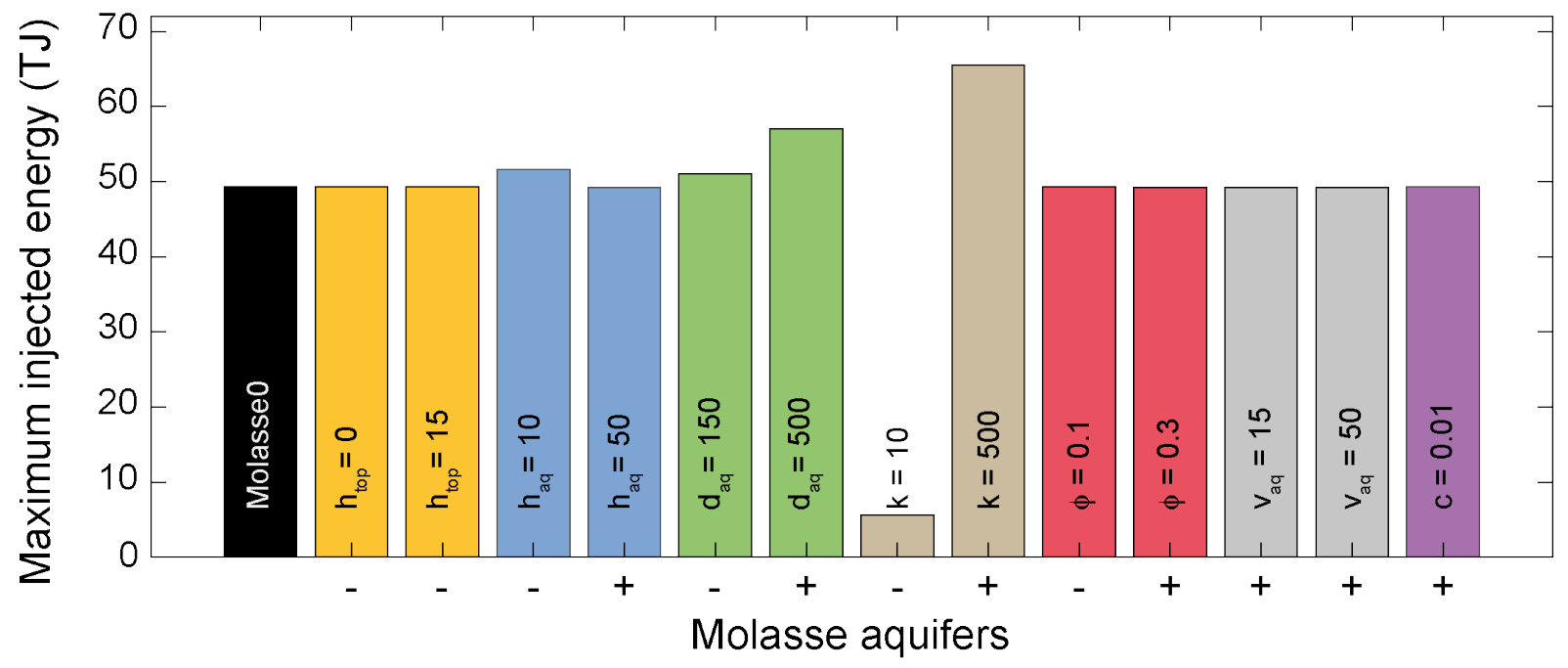

b.

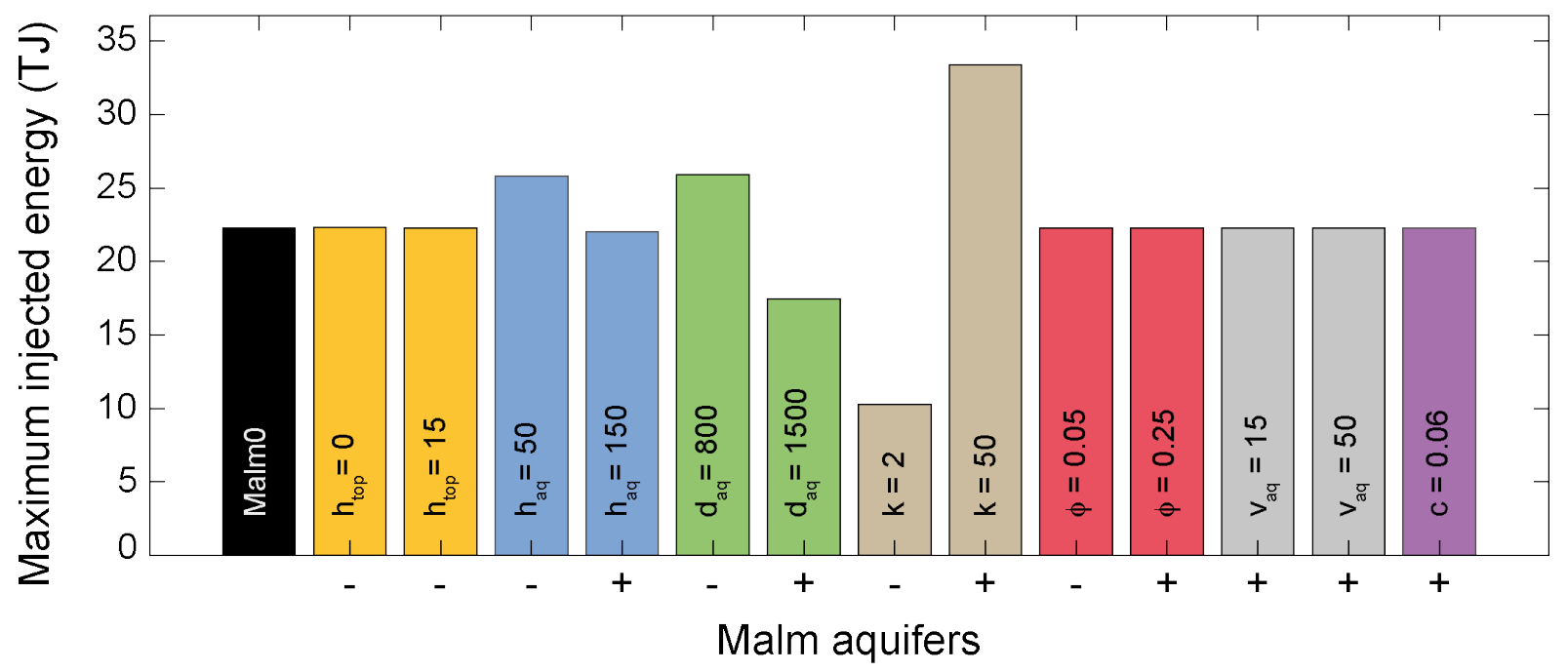

Figure 7: Maximum injected energy during a loading phase for the different Molasse (a.) and Malm (b.) aquifers. Investigated parameters are given in the figure for each simulation. Units and other constant parameters are given in Tables 1-2. Legend for the bar colours is given in Fig. 6. 

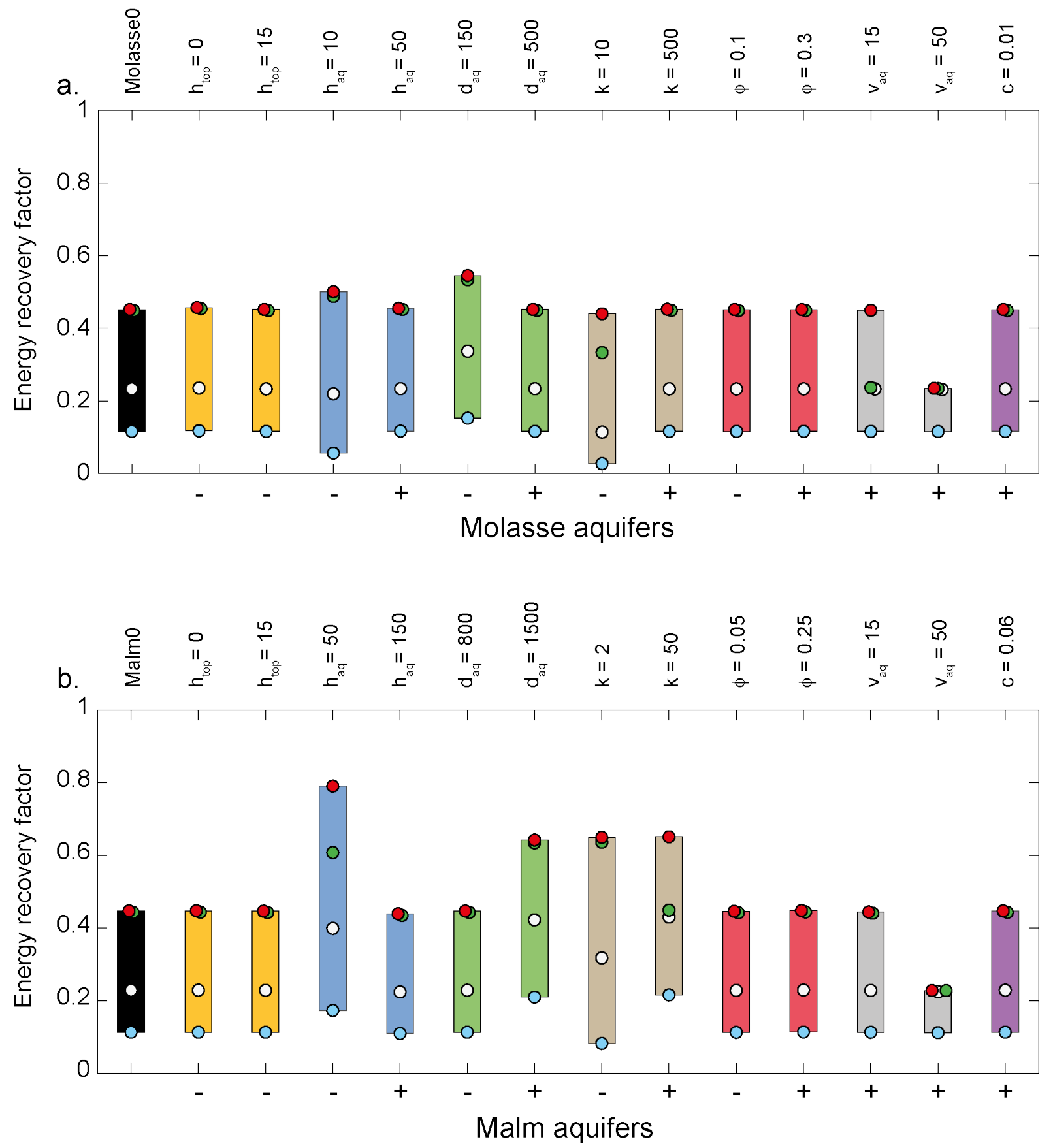

Figure 8: Energy recovery factor for the different Molasse (a.) and Malm (b.) aquifers after 1 (blue dots), 5 (white dots), 15 (green dots) and 20 (red dots) years, evaluated with a cut-off temperature at $\mathrm{T}_{\text {lim }}=80^{\circ} \mathrm{C}$. Investigated parameters are given in the figure for each simulation. Units and other constant parameters are given in Tables 1-2. Legend for the bar colours is given in Fig. 6. 
For the Molasse aquifers, the shallowest aquifer $\left(d_{\mathrm{aq}}=150 \mathrm{~m}\right)$ shows the best thermal performance after 20 years, with $\eta$ reaching 0.54 (Fig. 8a). This observation may seem counter-intuitive because at shallower depths the temperature contrast between the injected water and the aquifer is higher and thus the heat loss by conduction is expected to be larger than for Molasse0, resulting in a lower recovery. However, the quantity of injected/produced energy are also controlled by the bhp. In the case of a shallower aquifer, the pressure will be lower than for Molasse0 and the bhp limit might be reached later, resulting in a larger extracted volume of water. The thinnest Molasse aquifer $\left(h_{\mathrm{aq}}=10 \mathrm{~m}\right)$ has a slightly better energy recovery factor after twenty years than Molasse0, although it is lower for the first year (Fig. 8a). The surface contact between the aquifer top/bottom and the low-permeability rocks is larger than for Molasse0, resulting in a higher heat loss by conduction and thus a smaller recovery factor at the beginning of the HT-ATES exploitation. However, with time this heat loss is minimised as the low-permeability rock heats up, which increases the recovery factor.

For the Malm aquifers, the thinnest aquifer $\left(h_{\mathrm{aq}}=50 \mathrm{~m}\right)$ records the highest recovery factor after 20 years $(\eta=0.79)$ and also a better recovery factor than Malm0 after the first year (Fig. 8b). This behaviour can be explained by a better geometry of the energy stock. The heat plume is not as narrow as for Malm0 and temperature variations inside the aquifer are lower, which results in less heat conduction. The deepest aquifer $\left(d_{\mathrm{aq}}=1500 \mathrm{~m}\right)$ has a better energy recovery factor after 20 years than most other Malm aquifers, which can be explained by the lowest temperature contrast between the aquifer and injected water, leading to a smaller heat loss by conduction in the aquifer (Fig. 8b). Both Malm aquifers with a low and high permeability have a better energy recovery factor after twenty cycles than Malm0. This can be explained by the difference in injected volumes and injection rates controlled by the bhp limits (Fig. 8b).

Neither the thickness of the top layer, the aquifer porosity nor the salinity influence the energy recovery factor in our simulations. With the exception of the aquifer with no top layer, this lack of variation is expected, as no changes were observed in the size of the heat plume or the maximal injected energy for these simulations. For the case without an upper low-permeability layer, the more spherical shape of the stock may result in a better energy recovery factor and may compensate for the heat loss by convection and conduction in the upper part of the aquifer.

\subsection{Impact on the environment}

We monitor the temperature at two points in the model (see Fig. 3a) to evaluate the environmental impact of the HT-ATES exploitation. The first monitoring point (M1) is centred in the aquifer, $100 \mathrm{~m}$ away from the warm well in the direction of the cold well. We measure here the temperature increase at the end of the HT-ATES exploitation relative to the initial temperature. This allows us to control if the HT-ATES complies with the Swiss regulations, which specify that geothermal activities should 
not modify the natural groundwater temperature of more than $3^{\circ} \mathrm{C}(\mathrm{CH}-\mathrm{GSchV}, 1998$; OFEV, 2009). Temperature variations can, however, be higher locally, within a distance of $100 \mathrm{~m}$ from the wells. No monitoring point is placed close to the cold well as we observe in the reference models that the maximum temperature variation at this well was lower that $3^{\circ} \mathrm{C}$ (Fig. 5). The second monitoring point (M2) is placed $30 \mathrm{~m}$ above the warm well, and is used to estimate the efficiency of the insulating rock layer between two overlying aquifers. The temperature increase at this point is recorded throughout the HTATES exploitation. Finally, we also monitor the increase in the average aquifer temperature throughout the simulations. For M2 and the average aquifer temperature, we only report the maximum temperature increase (Fig. 9).

Temperature variations are much higher in the Molasse than in the Malm aquifers as the volume of injected warm water is larger and the initial aquifer temperature lower (Fig. 9). Only a few of the Molasse aquifers comply with the Swiss regulation: the aquifer without an upper low-permeability layer, the low permeability aquifer and the aquifer with the highest flow velocity (Fig. 9a). The temperature increase above the warm well does not exceed $10^{\circ} \mathrm{C}$ in the Molasse aquifers, with the exception of the aquifer without an insulating top layer where it reaches almost $60^{\circ} \mathrm{C}$. The average temperature of the aquifer generally does not increase more than $10^{\circ} \mathrm{C}$ with the exception of the thinnest aquifer $\left(h_{\mathrm{aq}}=10 \mathrm{~m}\right)$ and the shallowest $\left(d_{\mathrm{aq}}=150 \mathrm{~m}\right)$ (Fig. 9a). The investigated Malm aquifers comply with the Swiss regulations (Fig. 9b). The maximum temperature increase above the warm well does not exceed $4^{\circ} \mathrm{C}$ in the Malm aquifers, with the exception of the aquifer without an upper low-permeability layer, which records a temperature increase of approximately $10^{\circ} \mathrm{C}$. The Malm aquifers record a maximum increase between 2 and $4^{\circ} \mathrm{C}$ of their average temperature (Fig. 9b).

\section{Discussion}

\subsection{General observations and comparison with previous studies}

The environmental impact of the HT-ATES is positively correlated with the plume radius, $R_{\mathrm{th}, 30}$. Therefore, storing a large volume of heat into a thin, shallow and permeable aquifer might have a strong impact on the environment, and will not comply with the legal regulations in Switzerland.

The energy recovery factor depends on the shape of the thermal volume because energy losses by mechanical dispersion and conduction mostly occur at the boundary of the injected volume of water (Doughty et al., 1982; Bloemendal and Hartog, 2018). Assuming the injected volume can be simplified by a cylinder, Doughty et al. (1982) showed that the thermal recovery is inversely proportional to the ratio of thermal area to thermal volume:

$$
\frac{A_{t h}}{V_{t h}}=\frac{2 \pi R_{\mathrm{th}}^{2}+2 \pi R_{\mathrm{th}} h_{\mathrm{aq}}}{\pi R_{\mathrm{th}}^{2} h_{\mathrm{aq}}},
$$



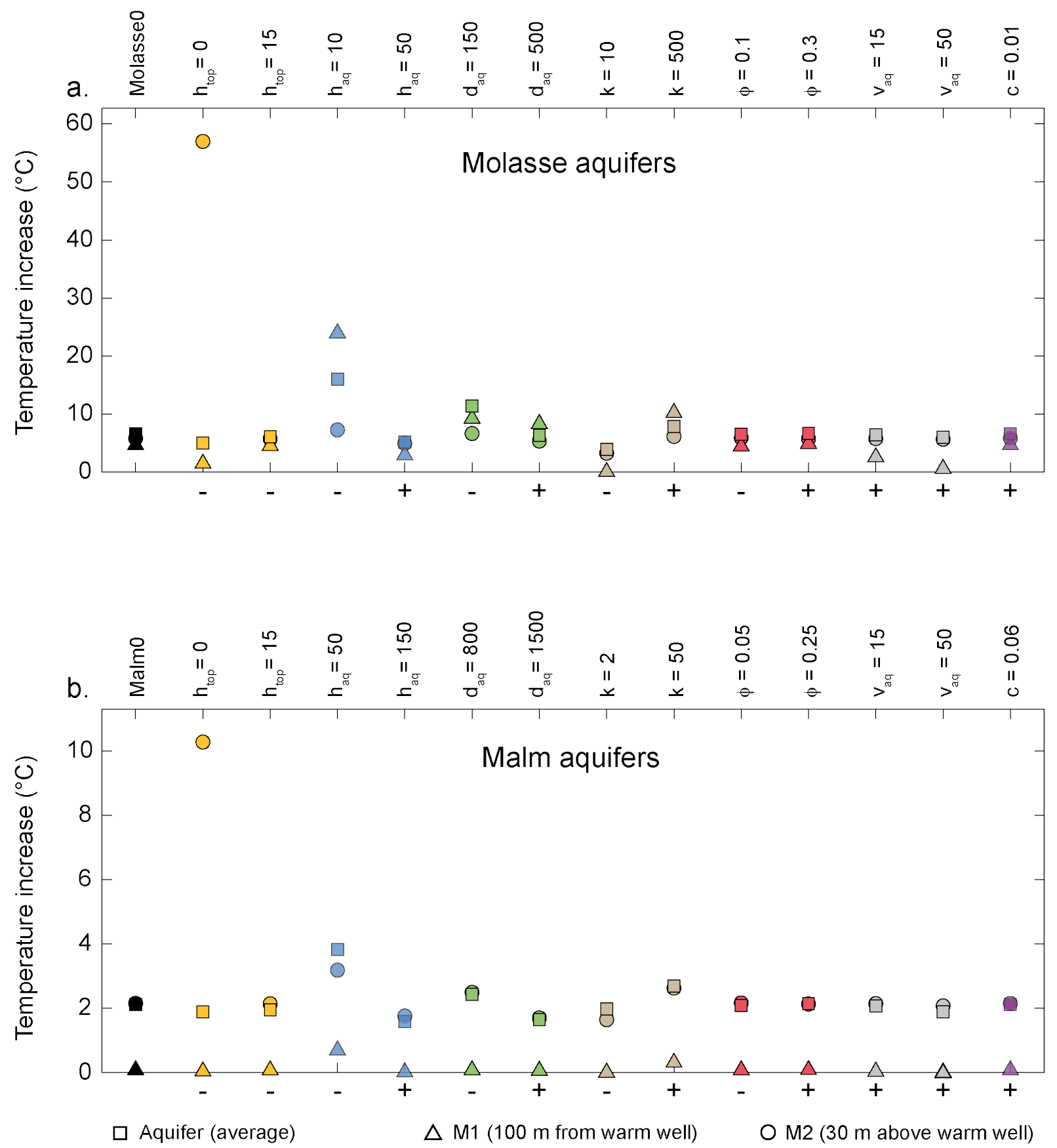

Figure 9: Monitoring of the temperature increase at different locations and times of the ATES exploitation for the Molasse (a.) and Malm (b.) aquifers. Circles: maximum temperature increase recorded $30 \mathrm{~m}$ above the warm well during the ATES exploitation. Triangles: temperature increase recorded $100 \mathrm{~m}$ away from the warm well at the end of the ATES exploitation. Squares: maximum increase of the aquifer average temperature during the ATES exploitation. Investigated parameters are given in the figure for each simulation. Units and other constant parameters are given in Tables 1-2. Legend for the point colours is given in Fig. 6. 
where $h_{\mathrm{aq}}$ is the aquifer thickness and $R_{\mathrm{th}}$ the thermal radius defined in eq. (6). The relationship is valid for equal injected and produced volumes and assuming that the injection well is perforated over the entire aquifer thickness. Buoyancy forces are also neglected. Doughty et al. (1982) also consider constant and equal injection and production rates, as well as a constant injection temperature. As such, these results are not directly applicable to our study. First, the energy recovery factor is evaluated with a cut-off temperature at $80^{\circ} \mathrm{C}$ so that the produced volume is much smaller than the injected volume. Secondly, even if equal injection and production rates are initially prescribed, they may vary during the cycles as bhp limits also restrict the pressure range in wells. Therefore, the injected/produced volumes in our simulations are usually smaller than the ones predicted by the relation $V=Q t$ as the bhp limits are often reached before the end of the injection period. This shows the importance of appropriately selecting the injection/production rates for a given reservoir to ensure that a critical pressure is not reached. Many of the previous studies consider constant and equal injection/production rates at each cycle, and do not mention the use of a limited pressure range (Kim et al., 2010; Sommer et al., 2013, among others). However, it is critical to ensure that no rock failure occurs, since this may result in loss of the entire thermal stock. The energy recovery factor in our parametric study remains limited because of the cut-off temperature, but reaches 0.8 to 0.9 when injected and produced volumes are equal (see. Figs 10-11), which is similar to previous studies for comparable injected volumes (Doughty et al., 1982; Van Lopik et al., 2016; Bloemendal and Hartog, 2018). The lowest energy recovery factor at the first cycle is observed for the simulation with the lowest injected volume for both the Malm and Molasse aquifers. This is consistent with the results from Doughty et al. (1982) who observed that the thermal recovery efficiency increases with the injected volume. Finally, the lowest energy recovery factor after twenty cycles is observed for the simulations with a groundwater flow of $50 \mathrm{~m} \mathrm{a}^{-1}$, which also agrees with previous studies (Courtois et al., 2006; Bloemendal and Hartog, 2018).

In addition to mechanical dispersion and conduction, thermal losses can also occur by buoyancy flow due to a density difference between the warm and cold water. This triggers a tilt of the thermal front, whose rate depends on the injected and aquifer water properties and aquifer permeability. This rate is given by an analytical characteristic tilting time (Hellström et al., 1979), defined as:

$$
t_{0}=\frac{h_{\mathrm{aq}}}{\sqrt{k^{h} k^{v}}} \frac{C_{a}}{C_{f}} \frac{\pi^{2}\left(\mu_{0}+\mu_{1}\right)}{32 G\left(\rho_{0}-\rho_{1}\right) g},
$$

where $h_{\text {aq }}$ is the aquifer thickness $(\mathrm{m}), k^{h}$ and $k^{v}$ are the horizontal and vertical aquifer permeabilities $\left(\mathrm{m}^{2}\right), C_{a}$ and $C_{f}$ are the aquifer and fluid volumetric heat capacities $\left(\mathrm{J} \mathrm{m}^{-3} \mathrm{~K}^{-1}\right)$, respectively. $\mathrm{G}$ is Catalan's constant $(\sim 0.915), \mathrm{g}$ is the gravitational constant $\left(9.81 \mathrm{~m} \mathrm{~s}^{-2}\right)$, whereas $\mu_{0} / \rho_{0}$ and $\mu_{1} / \rho_{1}$ are the viscosities $\left(\mathrm{kg} \mathrm{m}^{-1} \mathrm{~s}^{-1}\right) /$ densities $\left(\mathrm{kg} \mathrm{m}^{-3}\right)$ of the ambient and injected water, respectively. The tilting angle of an initially vertical front during a time $t_{0}$ is $\sim 60^{\circ}$ (Hellström et al., 1979). In our simulations, we do not observe a tilt of the thermal front during the injection, storage or production phases of the different cycles, although we consider a temperature-dependent density and viscosity. This can be explained by 
the very high characteristic tilting times estimated for the Molasse and Malm aquifers with respect to the injection period (120 days). Considering the temperature at the top of the aquifer (coldest) as the ambient temperature in Eq.(10), we estimated $t_{0}$ to be at least 5 times higher that the injection time for the Molasse aquifers, and more than hundred times higher for the Malm aquifers. Such high values for $t_{0}$ can however be explained by the low permeability of the aquifers. The aquifers investigated by Hellström et al. (1979) that presented strong tilts of the thermal front had permeabilities up to $10^{6} \mathrm{mD}$. Our investigated aquifers, on the contrary, are considered as very low- to low-permeable aquifers $(<1000$ $\mathrm{mD}$ ), with a maximum permeability of $500 \mathrm{mD}$. For comparison, a $40 \mathrm{~m}$ thick aquifer with an isotropic permeability of $100 \mathrm{mD}$ (equivalent to Molasse0) and injection and ambient temperatures at 120 and $20^{\circ} \mathrm{C}$, respectively, yields a tilt angle lower than $2^{\circ}$ after 270 days (Hellström et al., 1979). Our injection temperature being lower, the tilt is expected to be even smaller and will not be captured by the current grid resolution. Simulations at a significantly finer spatial resolution show a very small tilt, but no impact on the energy recovery factor is observed (see. suppl.mat.).

\subsection{Application of the model to the GGB and beyond}

The main economical application of the stored energy considered in our study is for direct heating of buildings, by re-injecting the warm water in one of the district heating systems in the Geneva Canton to compensate the heat deficit in winter. We consider that the stored water has an initial temperature of $90^{\circ} \mathrm{C}$ and it is re-injected at a minimum temperature of $80^{\circ} \mathrm{C}$ (based on the operative temperatures of the different heating networks). Currently, the warm water could be directly re-injected into the Cartigny and Aire-la-ville networks, or into the CADSIG and CADIOM networks, after optimisation (Faessler et al., 2015; Quiquerez et al., 2015). The parametric study reveals that for the considered well schedules (i.e. volume recovery factor close to one) and rates, the energy recovery factor generally remains low $(<0.6)$ because of the high cut-off temperature. The Malm aquifers show a slightly better recovery factor (up to 0.79$)$ than the Molasse aquifers $(<0.54)$ but have approximately $50 \%$ lower energy storage capacity. Storing the $35 \mathrm{Gwh}$ (or $126 \mathrm{TJ}$ ) of heat in excess would require approximately three and six pairs of wells for the Molasse and Malm aquifers, respectively. The Malm aquifers are at more than $1000 \mathrm{~m}$ depth and commonly four times deeper than the Molasse aquifers, and will thus have considerably higher drilling costs (Leamon, 2006). Therefore, the Molasse aquifers are probably more economically valuable than Malm aquifers, despite a lower energy recovery factor (Fig. 8). However, most of the Molasse aquifers do not comply with the Swiss regulations, which limit the temperature increase below $3^{\circ} \mathrm{C} 100 \mathrm{~m}$ away from the warm well at the end of the HT-ATES exploitation. On the contrary, all Malm aquifers satisfy this requirement.

Limiting the temperature rise and/or increasing the energy recovery factor could be achieved by investigating different well schedules and rates. Injecting at a lower rate or temperature will result in a smaller 
thermal perturbation. The economical application of the energy stored in the aquifer has a primary control on the HT-ATES thermal recovery because it determines the range of stored and extracted temperatures, as well as whether or not a cut-off temperature is imposed during the unloading phases. Having a cut-off temperature when simulating the unloading phases is likely to improve the thermal recovery factor because the aquifer will overall warm up more rapidly as a lower volume of the stored warm water is extracted. Similarly, the recovery factor can also be improved if the temperature difference between the stored water and the economical application is higher, i.e. if either the cut-off temperature is lower or if warmer water is initially injected in the aquifer. For example, the cut-off limit could be lowered to $55-60^{\circ} \mathrm{C}$ for direct heating of $4^{\text {th }}$ generation district heating (4GDH) systems (Lund et al., 2018). It could be further lowered for other low-energy applications such as heating of greenhouses, and coupled if necessary with heat-pumps depending on the temperature (Courtois et al., 2006). Storing the water at a warmer temperature would also be possible as the temperature in the CADSIG/CADIOM networks and outside the Cheneviers plant can be regulated (Faessler et al., 2015; Quiquerez, 2017).

We perform additional simulations for both aquifer types to evaluate the impacts of different economical strategies on the HT-ATES thermal performance and environmental impact. These simulations are compared with Molasse0 and Malm0 (Figs. 10-11) and the corresponding well parameters are reported in Table 3. The geometry of the aquifer and its thermal and physical properties are the same as for the reference models. The first simulation (Molasse1 or Malm1) employs different injection and production rates. No cut-off temperature is prescribed neither in the simulation nor in the post-processing when evaluating the energy recovery factor $\eta$ for the reference models and the first simulation. The other setups are simulated with injection and production rates equal to the reference models, but with different injection and cut-off temperatures (Table 3). For the Molasse aquifers, we investigate lower injection rates and temperatures in an attempt to comply with the swiss regulations. Instead, for the Malm we investigate higher injection rates and temperatures to improve $\eta$. 


\begin{tabular}{lcccccc}
\hline Simulations & $\begin{array}{c}\mathrm{Q}_{\text {inj }} \\
\mathrm{L} \mathrm{s}^{-1}\end{array}$ & $\begin{array}{c}\mathrm{T}_{\text {warm }} \\
{ }^{\circ} \mathrm{C}\end{array}$ & $\begin{array}{c}\mathrm{T}_{\text {cold }} \\
{ }^{\circ} \mathrm{C}\end{array}$ & $\begin{array}{c}\text { bhpmin } \\
\text { bar }\end{array}$ & $\begin{array}{c}\text { bhpmax } \\
\text { bar }\end{array}$ & $\begin{array}{c}\mathrm{T}_{\text {lim }} \\
{ }^{\circ} \mathrm{C}\end{array}$ \\
\hline \hline Molasse0 & 15 & 90 & 14.35 & 1 & 75 & none \\
Molasse1 & 7 & 90 & 14.35 & 1 & 75 & none \\
Molasse2 & 15 & 90 & 14.35 & 1 & 75 & 80 \\
Molasse3 & 15 & 90 & 14.35 & 1 & 75 & 60 \\
Molasse4 & 15 & 70 & 14.35 & 1 & 75 & 55 \\
Molasse5 & 15 & 70 & 14.35 & 1 & 75 & 30 \\
Molasse6 & 15 & 60 & 14.35 & 1 & 75 & 30 \\
\hline Malm0 & 10 & 90 & 39.26 & 1 & 250 & none \\
Malm1 & 15 & 90 & 39.26 & 1 & 250 & none \\
Malm2 & 10 & 90 & 39.26 & 1 & 250 & 80 \\
Malm3 & 10 & 90 & 39.26 & 1 & 250 & 60 \\
Malm4 & 10 & 120 & 39.26 & 1 & 250 & 80 \\
Malm5 & 10 & 120 & 39.26 & 1 & 250 & 100 \\
\hline
\end{tabular}

Table 3: Parameters employed for the simulations using different schedules. Rock and aquifer properties are the same as for the reference models (Table 2, Fig. 4).

The thermal radius $R_{\mathrm{th}, 30}$ varies between 30 and $150 \mathrm{~m}$ for the Molasse aquifers (Fig. 10a). Only Molasse 2 that employs a cut-off and injection temperatures at $80^{\circ} \mathrm{C}$ and $90^{\circ} \mathrm{C}$, respectively, has a wider plume radius than Molasse0. Molasse3 and Molasse0 show similar $R_{\mathrm{th}, 30}$ variations (Fig. 10a). This can be explained by the fact that for Molasse0, the temperature in the warm well does not drop below $60^{\circ} \mathrm{C}$ after the fourth cycle (Fig. 5). Therefore, a cut-off temperature at $60^{\circ} \mathrm{C}$ does not affect the volume of extracted fluid in subsequent cycles. Simulations with a lower injection temperature have slightly lower plume radius. The energy storage capacity is reduced when decreasing the injection rate or temperature (22 TJ for Molasse1 against 50 TJ for Molasse0, Fig. 10b). However, $\eta$ remains almost the same after 15 years (Fig. 10c). All the simulations have a similar $\eta$ of 0.8 after 15 years, with the exception of Molasse2 that reaches almost 0.9 (Fig. 10c). These are considerably better than for the parametric study (Fig. 8a). Simulations with a small temperature difference between the injected water and cut-off limit (Molasse2, Molasse4) tend to have a lower $\eta$ than Molasse0 during the first years, but they are comparable after 15 years. Only Molasse1 that has an injection rate at $7 \mathrm{~L} \mathrm{~s}^{-1}$ complies with the Swiss regulations (Fig. 10d). Molasse2 records the highest temperature increase for M1 (taken $100 \mathrm{~m}$ away from the warm well at the end of the HT-ATES exploitation) with more than $10^{\circ} \mathrm{C}$. The other simulations show a temperature increase for $\mathrm{M} 1$ around $4^{\circ} \mathrm{C}$. In addition to the simulations presented here, we also ran a simulation with the same properties as for Molasse 0 but with an injection rate at $10 \mathrm{~L} \mathrm{~s}^{-1}$. The simulation satisfies the swiss regulations with a temperature increase for $\mathrm{M} 1$ of $2.6^{\circ} \mathrm{C}$. The maximum injected energy per cycle reaches $33 \mathrm{TJ}$, suggesting that four wells will be necessary to store the annual $35 \mathrm{GWh}$ of excess energy. 
$R_{\text {th,30 }}$ ranges from 10 to $50 \mathrm{~m}$ for the Malm aquifers (Fig. 11a), and is wider for simulations with a higher injection rate (Malm1) or when $T_{\lim } \geq 80^{\circ} \mathrm{C}$ (Malm2, Malm4 and Malm5) than for Malm0. The largest $R_{\mathrm{th}, 30}$ are observed in simulations with injection temperature at $120^{\circ} \mathrm{C}$. The amount of injected energy increases by approximately $70 \%$ (from $22 \mathrm{TJ}$ to $38 \mathrm{TJ}$ ) for simulations with a warmer injected water or a higher injection rate compared to Malm0 (Fig. 11b). Overall, $\eta$ improves compared to the parametric study (Fig. 8b) and reaches 0.8 after 15 years (Fig. 11c). A higher injection temperature yields lower energy recovery factors compared to Malm0 in the first cycles, but they are similar after five years. Malm2 has a low energy recovery factor after the first year but it improves in the long term and reaches 0.8. All the Malm aquifers comply with the Swiss regulations (Fig. 11d). The simulations with the highest injection temperature record the largest temperature increases in the aquifer and above the warm well (Fig. 11d). This can be explained by both the wider heat plume and higher temperature difference between the injected water and the aquifer.

Generally, $\eta$ can be improved considerably by either imposing a cut-off temperature during the unloading phases or by using the extracted water at lower temperature (Figs. 10-11c). Installing 4GDH systems, operating with supply temperatures around $55^{\circ} \mathrm{C}$ (Lund et al., 2018), in new neighbourhoods could contribute to increase the thermal recovery. It will also allow the storage at lower temperatures, thereby restricting the thermal perturbation. Other low-temperature applications like greenhouse heating can also be considered to maximise the use of the produced water. All investigated Malm aquifers comply with the Swiss regulations and represent an interesting target for storage above $90^{\circ} \mathrm{C}$. Although few of the Molasse aquifers investigated in the parametric study comply with the Swiss regulations, the Molasse deposits can still represent a target for heat storage if the volume of injected water is limited. Only reducing the temperature of the injected water does not effectively limit the temperature increase below the legal regulations. In this case, the Molasse aquifers are an economically more valuable target for storage at temperature below $90^{\circ} \mathrm{C}$ than the Malm aquifers, which also require at least four wells to store the annual excess of energy (Fig. 7b).

This study represents a first investigation of the storage possibilities in the Molasse and Malm units of the GGB and highlights the importance of some physical parameters. The porosity when not linked to permeability, the salinity and the aquifer flow velocity up to $15 \mathrm{~m} \mathrm{a}^{-1}$ have no impact on the HT-ATES performance nor its environmental impact. The values used for the salinity are larger than the measured values in the GGB (Rusillon, 2017), indicating that this parameter may be neglected in future studies investigating HT-ATES performance. However, saline water could be a problem from an operational aspect, as it may cause scaling in wells (Jenne et al., 1992). The energy recovery factor in the long term is not affected for aquifer flow velocities up to $15 \mathrm{~m} \mathrm{a}^{-1}$, which is consistent with previous studies (Courtois et al., 2006). However, we notice a time delay to reach the maximum energy recovery factor for the Molasse aquifers (see Fig. 8a compared to Fig. 8b, and reference models). Finally, a $15 \mathrm{~m}$ thick low-permeability rock unit seems to sufficiently limit the temperature increase in shallower units (same 

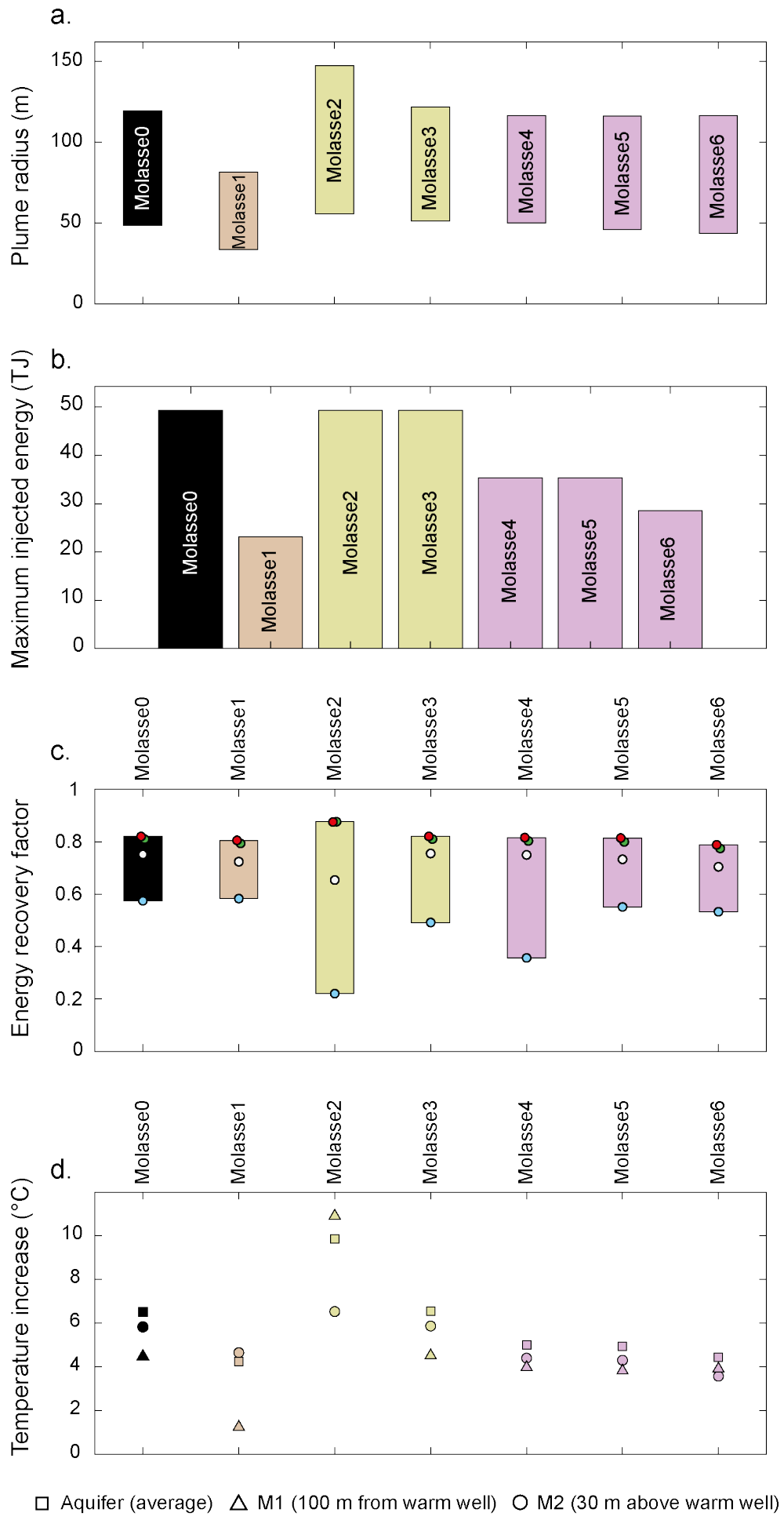

Figure 10: a. Variations of the heat plume radius during the ATES exploitation, b. maximal injected energy during a loading phase, c. energy recovery factor and $\mathbf{d}$. temperature monitoring for a Molasse aquifer with different scheduling strategies. Blue, white, green and red dots: energy recovery factor after 1, 5, 15 and 20 years, respectively. Circles: maximum temperature increase recorded $30 \mathrm{~m}$ above the warm well during the ATES exploitation. Triangles: temperature increase recorded $100 \mathrm{~m}$ away from the warm well at the end of the ATES exploitation. Squares: maximum increase of the aquifer average temperature during the ATES exploitation. Rock and aquifer properties are the same as for Molasse0. Parameters for the different well schedules are given in Table 3. 
a.

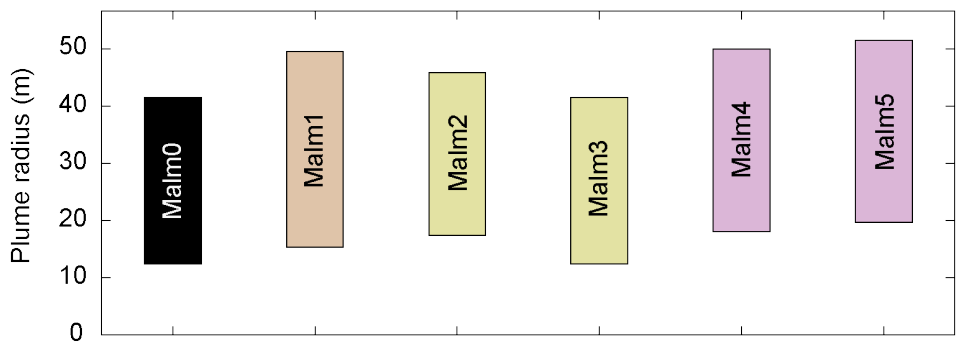

b.
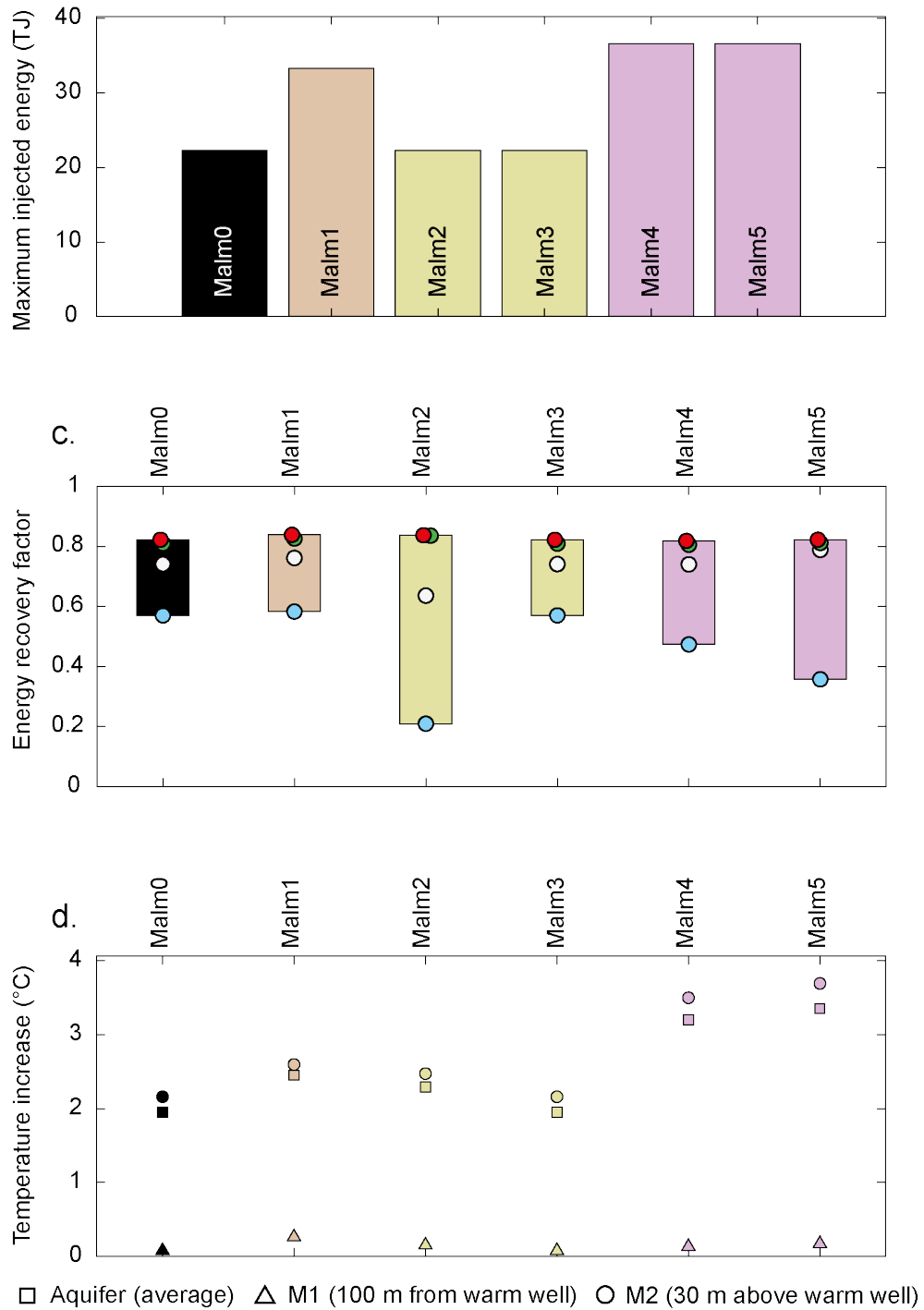

Figure 11: a. Variations of the heat plume radius during the ATES exploitation, b. maximal injected energy during a loading phase, c. energy recovery factor and $\mathbf{d}$. temperature monitoring for a Malm aquifer with different scheduling strategies. Blue, white, green and red dots: energy recovery factor after 1, 5, 15 and 20 years, respectively. Circles: maximum temperature increase recorded $30 \mathrm{~m}$ above the warm well during the ATES exploitation. Triangles: temperature increase recorded $100 \mathrm{~m}$ away from the warm well at the end of the ATES exploitation. Squares: maximum increase of the aquifer average temperature during the ATES exploitation. Rock and aquifer properties are the same as for Malm0. Parameters for the different well schedules are given in Table 3. 
environmental impact with a 15 or $50 \mathrm{~m}$ thick layer, Fig. 9). The temperature increase $30 \mathrm{~m}$ above the warm well is between 2 and $4{ }^{\circ} \mathrm{C}$ and between 4 and $6^{\circ} \mathrm{C}$ for Malm0 and Molasse0, respectively, depending on the employed well schedule (Figs. 10d-11d). Groundwater chemistry can be altered by temperatures changes since temperature affects many processes, such as solubility of minerals, reaction kinetics, oxidation of organic matter, or even redox processes (Brons et al., 1991; Sowers et al., 2006; Bonte et al., 2013). The magnitude of these effects depends on the initial water chemistry and temperature, as well as the temperature variations. The effects of temperature on mineral equilibrium remain limited for small temperature rise and at low temperature $\left(<25^{\circ} \mathrm{C}\right)$ (Drijver, 2011; Hartog et al., 2013; Possemiers et al., 2014). Based on the Arrhenius equation, reaction kinetics are not significantly influenced by temperature changes lower than $20^{\circ} \mathrm{C}$ (Possemiers et al., 2014). The use of groundwater for drinking and process water can be limited for temperature higher than $25^{\circ} \mathrm{C}$ due to the reduction of metal oxides and possible release of heavy metals from sediments (Jesußek et al., 2012). The initial temperature of the shallower aquifer, $30 \mathrm{~m}$ above the warm well, is about 14 and $38^{\circ} \mathrm{C}$ for Molasse 0 and Malm0, respectively. For Molasse0, the maximum temperature increase yields a temperature of $20^{\circ} \mathrm{C}$, suggesting that the temperature will have little influence on the drinking water quality. For Malm0, the initial temperature is already close to $40^{\circ} \mathrm{C}$ and likely too high for a good quality of drinking water. In absence of detailed data concerning the water chemistry in the GGB, it is difficult to predict the impact of a temperature rise on water quality. Further studies are thus required.

The investigated Molasse aquifers are considered to be sandstone channel bars, surrounded by very-low permeable siltstones and claystones, and thus represent interesting isolated reservoirs for storage. Despite a small lateral extension, the river beds can be stacked on top of each other, forming a single reservoir. This allows having a larger, yet laterally localised storage, which can be of great importance for thermal recovery efficiency or when planning HT-ATES systems in densely populated areas (Doughty et al., 1982; Sommer et al., 2015). The Molasse deposits constitute a quasi-continuous unit along the Alps Mountains, from France to Austria, where such alternating sandstone channel bars and clay deposits can be found, and could be considered for heat storage. In particular, the HeatStore ${ }^{1}$ project aims at developing an ATES experimental site near Bern, Switzerland. Since the Molasse exhibits similar heterogenities in its properties across the Alps, the results shown here are relevant for the scientific community working in other regions. The approach used in this study can be applied to other highly heterogeneous reservoirs of the Molasse basin. While the legal temperature increase is limited to $3^{\circ} \mathrm{C}$ in Switzerland for geothermal application, it can reach up to $11^{\circ} \mathrm{C}$ in France (Hähnlein et al., 2010), which offers more flexibility. Austria, on the other hand, is more restrictive and limits geothermal activities in a temperature range between 5 and $20^{\circ} \mathrm{C}$. With the necessity to reduce carbon emissions, heat storage is a developing and promising technology to recycle the large amount of heat wasted by the industrial sector. The prospecting of new reservoirs is thus important and sand bars of the Molasse deposits could represent a potential target for

\footnotetext{
${ }^{1}$ https://www.heatstore.eu/
} 
low- to moderate-temperature storage $\left(<90^{\circ} \mathrm{C}\right)$. More generally, this type of reservoir architecture and sedimentary deposits can be interesting for heat storage due to their high permeability and limited lateral extension (i.e. isolated reservoir) and are commonly found in foreland basins. Recently, Winterleitner et al. (2018) investigated the possibility of heat storage in such sandstone channel bars in Oman.

\subsection{Limitations of the study}

The HT-ATES performance and environmental impact for the Molasse and the Malm stratigraphic units were evaluated using the currently available data for the GGB and considering Swiss regulations. It is worth noting that the majority of the wells considered by Rusillon (2017), who provided a first review of the rock permeability and porosity, were drilled in France. Similarly, their outcrop samples mostly originated from France. Moreover, thermal rock properties for the GGB are not constrained and average values for sedimentary rocks were taken from the literature for our study. Due to the strong heterogeneity of the rock properties in the GGB, the extrapolation of the data from Rusillon (2017) and the literature for our model may not be sufficient to evaluate the full potential and feasibility of heat storage in the Geneva Canton. More data need to be acquired near Geneva to fully characterise the physical and thermal properties of the aquifers.

Furthermore, some processes are not considered in our model, or have been simplified. The Malm aquifers are mostly fractured or karstified (Signer and Gorin, 1995; Signorelli et al., 2004). There is thus a difference in porosity and permeability between the rock matrix and the fractures, which may result in different flow velocities. In theory, a dual-porosity model should be employed to investigate the Malm aquifers for which the fracture size, porosity and permeability are defined. However, in absence of consistent and reliable data for the fractures, we believe a model of fluid flow in a porous medium is a fair approximation for a preliminary evaluation of the aquifer potential for heat storage. Constraining the Malm fractures permeability and porosity is not only important for the choice of the appropriate model, but is above all crucial to simply evaluate the feasibility of heat storage in these aquifers. High permeability fractures would result in the loss of the stored heat after the summer. The use of our model to simulate the Molasse aquifers is however perfectly justified as the investigated reservoirs are sandstones with little to no fractures (Platt and Keller, 1992; Chevalier et al., 2010). We have considered in this study homogeneous isotropic permeabilities and porosities, representative of the average values for the Malm and Molasse aquifers. In reality, these parameters show strong spatial variations and could significantly affect the HT-ATES performance and its environmental impact (Sommer et al., 2013). A few measurements are available for the permeability anisotropy in the GGB, indicating a ratio of vertical to horizontal permeability of 0.9 and 1.2 for the Molasse and Malm aquifers, respectively (Rusillon, 2017). Simulations (not reported here) with varying horizontal to vertical permeability ratio for both Malm and Molasse aquifers show no notable effect of this anisotropy on the HT-ATES performance. This is expected, 
because in a homogeneous aquifer with a well perforated over its entire thickness, the flow is dominantly lateral during the loading and unloading phases. Although we only considered measurements done on sandstones to characterise the petrophysical properties of the Molasse aquifers, previous studies revealed a strong variability, with permeabilities ranging from 0.1 to $1300 \mathrm{mD}$ and porosities between 0.04 and 0.32 (Rusillon, 2017). To evaluate the effect of an heterogeneous aquifer on the performance of a HT-ATES, we perform two simulations with different permeability and porosity distributions (Fig. 12a,b). All other aquifer and well parameters are the same as for Molasse0. We generate a field by a Gaussian process, where 20 independent layers were sampled from the same distribution. Permeability is assumed to be lognormally distributed, with a normal distribution for the porosity. The porosity is directly correlated with the logarithm of the permeability and varies between 0.001 and 0.37 .

Heterogeneous aquifers display a more random distribution of the thermal perturbation due to preferential flow direction (Fig. 12c,d). The heat plume is no longer cylindrical as in the previous simulations and its shape is controlled by the most permeable parts of the aquifer. For the first simulation, the aquifer is quite tight around the injection well and the heat does not propagate very far in the aquifer (Fig. 12c). Although not completely cylindrical, the shape of the heat plume is similar to those in the previous homogeneous simulations. The second simulated aquifer has a higher permeability towards the bottom of the aquifer, whereas its upper part has a very low permeability. This results in a conical thermal plume (Fig. 12d). The energy stored in the aquifer is $\sim 25 \%$ higher for the second simulation than the first, mostly due to a higher permeability around the injection well and a generally slightly higher permeability in the aquifer (Fig. 12a-e). The energy recovery factor $\eta$ is calculated without any cut-off temperature. For the first simulation, $\eta$ still remains below 0.5 after 20 years, which is about $50 \%$ of the observed value for Molasse0 (Fig. 10c, Fig. 12f). For the second simulation, $\eta$ is only $6 \%$ lower than for Molasse0. This latter difference is in a range of those expected between heterogeneous and homogeneous aquifers (Sommer et al., 2013). These simulations show the importance of characterising the permeability and porosity patterns in heterogeneous aquifers so that the wells can be placed ideally to limit the reduced thermal recovery.

Aspects such as rock mechanics or rock-fluid interactions are not addressed in this study. We consider an upper bhp limit in our model that roughly corresponds to the average lithostatic pressure in the aquifer, but we do not use a more precise failure criterion. Our model only investigates fluid flow and is not coupled to a mechanical model that could for example investigate the ground deformation during loading or unloading phases (e.g. poro-elastic model, (Biot, 1941)). However, as the HT-ATES uses pairs of wells to ensure a volume balance and limit inflation or deflation in the reservoir, the subsequent ground deformation should remain limited. Dissolution of rock minerals and subsequent re-precipitation, as well as microbiological processes may considerably affect the HT-ATES performance by modifying the permeability and porosity in the aquifer (Brons et al., 1991; Jenne et al., 1992). The intensity and kinetics of the reactions will depend on the water chemistry, temperature, pressure and $\mathrm{pH}$. These processes 


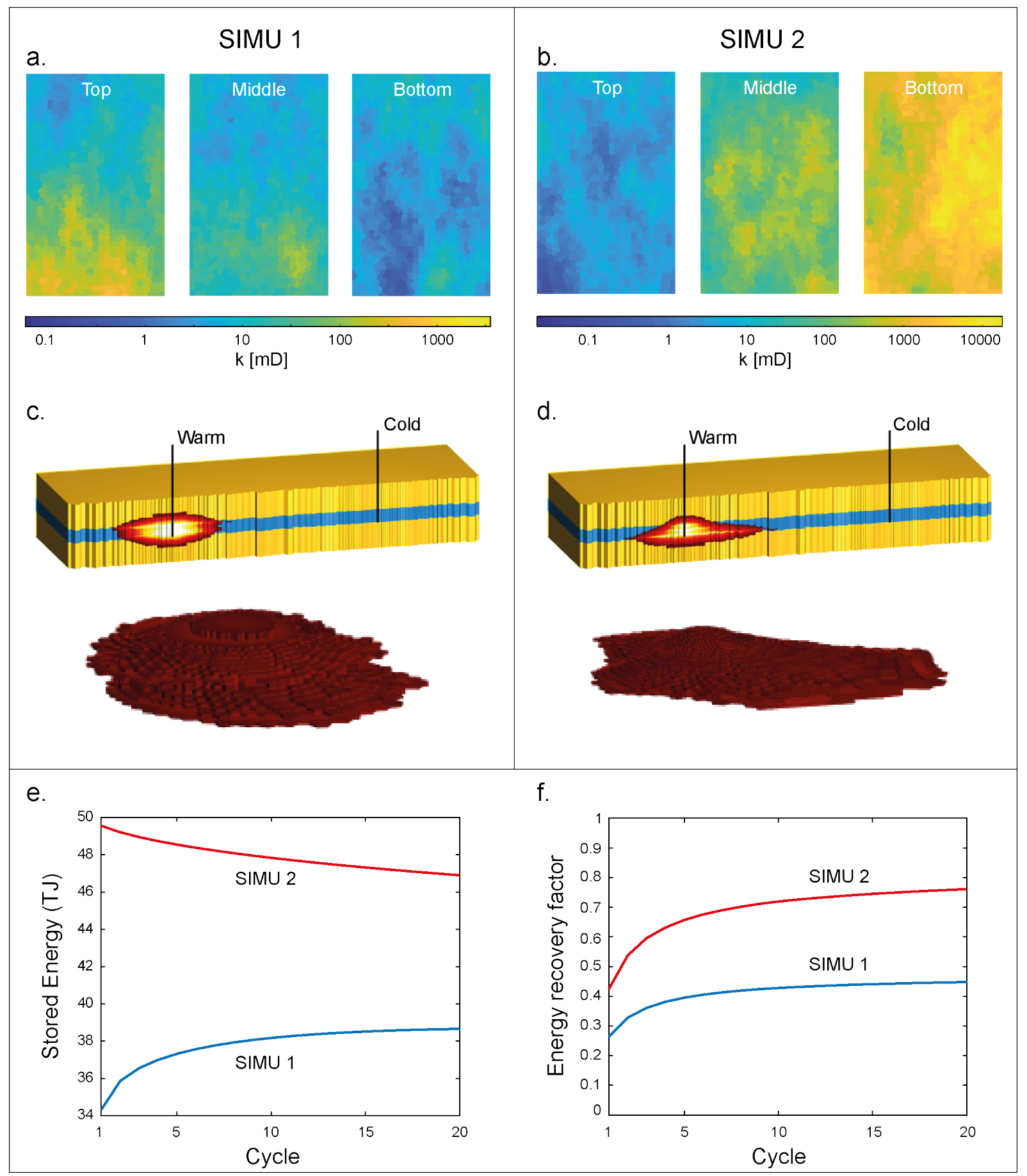

Figure 12: a,b Permeability distribution at the top, middle and bottom of the aquifers. Logarithmic scale. c,d Cross section of the model and extracted plume at the beginning of the unloading phase for the $10^{\text {th }}$ cycle e. Evolution of the injected energy during the HT-ATES exploitation. f. Evolution of the energy recovery factor during the HT-ATES exploitation. 
could further be investigated in numerical models when fully assessing the HT-ATES performance and its environmental impact. It is currently not possible to conclude on the aquifer flow velocity from the available discharge rates measured at the wells in the GGB. Further investigations are required as velocities larger than 15-20 $\mathrm{m} \mathrm{a}^{-1}$ have a considerable impact on the HT-ATES thermal recovery (Fig. 8). For large aquifer velocities $\left(>50 \mathrm{~m} \mathrm{a}^{-1}\right)$, storage is not ideal but several strategic options can be taken. If the velocity drift is sufficiently high, the stored energy could be recovered at a second well. In this case, one well will always operate in an injection mode and the other in a production mode. Bloemendal and Olsthoorn (2018) also suggested to use multiple pairs of warm and cold wells. Another option is to place the wells ideally close to a structural trap (e.g. sealed fault) that confines the warm water during the storage period.

Finally, we have employed in our study the same well schedule over 20 years, considering constant energy availability and demands. In reality, this is unlikely to be the case and the loading-unloading phases should be adapted to the true energetic needs and available sources of heat. Integrating the energy demands with meteorological data over a longer period and considering up-to-date energy policy and technical advances will help forecasting the future needs and demands for the Canton of Geneva and further constrain the HT-ATES performance.

\section{Conclusions}

Our new geothermal module in MRST allows for intuitive and rapid testing of HT-ATES strategies involving complex injection schedules, as well as for various geothermal applications. MRST is an opensource software released under the GPL 3 license, where the source code for all parts of the simulator can be modified easily. While a number of compiled, third-generation language implementations of similar functionality exists, high-quality $\mathrm{C}++$ or Fortran implementations require a large amount of domainspecific knowledge from users who wish to modify the inner workings of the simulator. We hope that a implementation in a high-level, fourth-generation language will be more widely accessible to users who wish to write their own simulators.

The results of our study allow us to decipher the relative importance of some of the investigated parameters and their control on thermal recovery efficiency and shows that the. performance of the HT-ATES will not be affected by the salinity nor by aquifer velocities lower than $15 \mathrm{~m} \mathrm{a}^{-1}$. Typical salinities encountered in the first $2 \mathrm{~km}$ of sedimentary basins or aquifer flow velocities lower than $15 \mathrm{~m} \mathrm{a}^{-1}$ do not affect the thermal recovery. Porosity changes if not linked to permeability will also not affect the HT-ATES performance. Thermal losses by conduction, and thus thermal recovery, can no longer be derived from the aspect ratio of the stored warm water when bhp limits control the injected/produced volumes. The effects of bhp limits on the injected/produced volumes, and subsequent thermal recovery are even more 
pronounced in heterogeneous aquifers if the wells are not placed carefully. Moreover, for such aquifers the shape of the stored volumes of warm water and its impact on thermal recovery are hard to predict. High-permeability and fairly homogeneous aquifers represent interesting targets for seasonal HT-ATES systems because they can store large amount of heat in a limited time-window. On the other hand, they also favour thermal losses by free convection, and thus limit the thermal recovery. Our results show that for aquifer permeabilities below $500 \mathrm{mD}$, thermal losses by convection are strongly reduced, even absent in some cases, and the thermal recovery factor reaches up to 0.9. These aquifers, however, have limited seasonal storage volume, as the injection and production rates are scaled with the permeability to avoid rock fracturing.

This study highlights the importance of thorough numerical simulations to evaluate the thermal performance of an HT-ATES system in more realistic exploitation conditions before its realisation. Its optimisation can only be achieved through a global energy policy at the county scale that promotes the development of renewable energies, low-energetic heating facilities and constrained forecasts of the future energetic demands. For the specific case of the Chenevier plant, near Geneva, two approaches can be undertaken to exploit the $\sim 35 \mathrm{GWh}$ in excess of heat. The first is to apply a cut-off temperature during the unloading phases and stop extracting the warm water when its temperature drops below $80^{\circ} \mathrm{C}$. The energy recovery factor is expected to be low in the first cycles but to improve considerably with time and reach 0.8. The aquifer will, however, significantly warm up, which can have a strong impact on the environment. The second approach is to keep a volume recovery factor close to one but only inject in the district heating networks the water at a temperature higher than $80^{\circ} \mathrm{C}$. The environmental impact is limited but the energy recovery factor generally remains below 0.5 . This can be improved if the extracted water is exploited at lower temperatures, either by optimisation of the existing networks or by diversification of the economical applications. The Molasse aquifers are economically more viable than the Malm aquifers for storage up to $90^{\circ} \mathrm{C}$ because of their lower drilling costs for comparable energy recovery factors. The thermal perturbations in these aquifers are non-negligible, which means that the volume of injected water must be controlled to comply with the environmental regulations in Switzerland. The Malm aquifers become, however, interesting for heat storage above $90^{\circ} \mathrm{C}$ because of their limited environmental impact. More in-situ data are required to characterise the spatial variations of the aquifer properties in the Geneva Canton to provide a more detailed assessment of the economical and environmental impacts of heat storage. Thermo-mechanical and thermo-chemical processes should also be integrated in further modelling study. Nevertheless, the methodology and approach presented in this study can be applied to other heterogeneous aquifers of the Molasse Basin and more generally in foreland basins, where such type of isolated and spatially limited reservoirs are commonly found. 


\section{Acknowledgment}

M. Collignon and M. Alcanié were funded by GENERATE, SNF project (PYAPP2_66900, PI Matteo Lupi). M. Lupi is a SCCER-SoE Professor supported by KTI funding. M. Collignon is now funded by a Marie Skłodowska-Curie Individual Fellowship (NERUDA 793662). Ø. S. Klemetsdal was supported by the Research Council of Norway under grant no. 244361. O. Møyner was funded by VISTA, which is a basic research programme funded by Equinor and conducted in close collaboration with The Norwegian Academy of Science and Letters. The authors would like to thank the SIG (Services Industriels de Genève), and in particular Michel Meyer and Loic Quiquerez, for providing internal reports and the data for Figure 2, as well as Thomas Driesner for providing a table with computed parameters (i.e. fluid density, viscosity, enthalpy and heat capacity). The authors also thank Nicole Lupi, Knut-Andreas Lie and Luca Guglielmetti for fruitful discussions. Finally, two anonymous reviewers and the Editor, Christopher Bromley, are thanked for their comments on a previous version of the manuscript.

\section{References}

Amberger, G.

1978. Contribution à l'étude du quaternaire de la région lémanique: Résultats de quelques sondages profonds exécutés à genève. Eclogae Geologicae Helvetiae, 71:193-206.

Andersson, O. 2007. Aquifer thermal energy storage (ates). In Thermal Energy Storage for Sustainable Energy Consumption. NATO Science Series (Mathematics, Physics and Chemistry)., H. Paksoy, ed., volume 234, Pp. $155-176$. Dordrecht: Springer.

Baujard, C., S. Signorelli, T. Kohl, and S. G. Kommission

2007. Atlas des ressources géothermiques de la Suisse occidentale: domaine Sud-Ouest du Plateau Suisse, Contribution à la géologie de la Suisse. Géophysique. Commission Suisse de Géophysique.

Becker, D., G. Rauber, and L. Scherler

2013. New small mammal fauna of late middle eocene age from a fissure filling at la verrerie de roches (jura, nw switzerland). Revue de Paléobiologie, 32:433-446.

Berge, R. L., Ø. S. Klemetsdal, and K.-A. Lie 2018. Unstructured voronoi grids conforming to lower dimensional objects. Comput. Geosci. In press.

Biot, M.

1941. General theory of three-dimensional consolidation. Journal of Applied Physics, 12:155-164.

Bloemendal, M. and N. Hartog

2018. Analysis of the impact of storage conditions on the thermal recovery efficiency of low-temperature ates systems. Geothermics, 71:306-319. 
Bloemendal, M., M. Jaxa-Rozen, and T. Olsthoorn

2018. Methods for planning of ates systems. Applied Energy, 216:534-557.

Bloemendal, M. and T. Olsthoorn

2018. Ates systems in aquifers with high ambient groundwater flow velocity. Geothermics, 75:81-92.

Bloemendal, M., T. Olsthoorn, and F. Boons

2014. How to achieve optimal and sustainable use of the subsurface for aquifer thermal energy storage. Energy Policy, 66:104-114.

Blondel, T.

1990. Lithostratigraphie synthétique du jurassique et du crétacé inférieur de la partie septentrionale de la montagne du vuache. Archives des Sciences, Genève, 43:175-191.

Bonte, M., B. M. van Breukelen, and P. J. Stuyfzand

2013. Temperature-induced impacts on groundwater quality and arsenic mobility in anoxic aquifer sediments used for both drinking water and shallow geothermal energy production. Water Research, 47:5088-5100.

Brentini, M.

2018. Impact d'une donnée géologique hétérogène dans la gestion des géo-ressources: analyse intégrée et valorisation de la stratigraphie à travers le bassin genevois (Suisse, France). PhD thesis.

Brons, H., J. Griffioen, C. Appelo, and A. Zehnder

1991. (bio)geochemical reactions in aquifer material from a thermal energy storage site. Water Research, 25:729-736.

Buscheck, T. A., J. M. Bielicki, and J. B. Randolph

2017. $\mathrm{Co}_{2}$ earth storage: Enhanced geothermal energy and water recovery and energy storage. Energy Procedia, 114:6870-6879.

\section{CH-GSchV}

1998. Gewässerschutzverordnung vom 28. Oktober 1998 (Water Protection Order). Schweizer Bundesrat.

Charollais, J.-J., M. Weidmann, J.-P. Berger, B. Engesser, J.-F. Hotellier, G. Gorin, B. Reichenbacher, and P. Schäfer

2007. La molasse du bassin franco-genevois et son substratum. Archives des Sciences, 60:59-174.

Charollais, J.-J., R. Wernli, B. Mastrangelo, J. Metzger, R. Busnardo, B. Clavel, M. Conrad, E. Davaud, B. Granier, M. Saint Martin, and M. Weidmann

2013. Présentation d'une nouvelle carte géologique du vuache et du mont de musièges (haute-savoie, france). Archives des Sciences, 66:1-64.

Chelle-Michou, C., D. D. Couto, A. Moscariello, P. Renard, and E. Rusillon

2017. Geothermal state of the deep western alpine molasse basin, france-switzerland. Geothermics, 67:48-65. 
Chevalier, G., L. W. Diamond, and W. Leu

2010. Potential for deep geological sequestration of $\mathrm{co}_{2}$ in switzerland: a first appraisal. Swiss Journal of Geosciences, 103:427-455.

Choffat, M.

1878. Sur le callovien et l'oxfordien dans le jura. Bulletin de la société géologique de France, 6:358-364.

Collignon, M., A. Mazzini, D. W. Schmid, and M. Lupi

2018a. Modelling fluid flow in active piercements: Challenge and approaches. Marine and Petroleum Geology, 90:157-172.

Collignon, M., D. W. Schmid, C. Galerne, M. Lupi, and A. Mazzini

2018b. Modelling fluid flow in clastic eruptions: Application to the lusi mud eruption. Marine and Petroleum Geology, 90:173-190.

Colombo, U.

1992. Development and the global environment. In The energy-environment connection, J. Hollander, ed., Pp. 3-14. Washington, D.C.: Island Press.

Conrad, M.-A.

1969. Les calcaires urgoniens dans la région entourant genève. Eclogae Geologicae Helvetiae, 62:1-79.

Courtois, N., J.-P. Marchal, A. Menjoz, P. Monnot, Y. Noël, V. Petit, D. Thiéry, A. Grisey, and D. Grasselly 2006. Application du stockage thermique en aquifère au chauffage et au refroidissement de serres maraîchères en France: étude de préfaisabilité. BRGM.

Dickinson, J., N. Buik, M. Matthews, and A. Snijders 2009. Aquifer thermal energy storage: theoretical and operational analysis. Géotechnique, 59:249-260.

Diesler, C.

1914. Stratigraphie und Tektonik des Rotliegenden und der Trias beiderseits des Rheins zwischen Rheinfelden und Augst. PhD thesis.

Dincer, I.

1998. Energy and environmental impacts: Present and future perspectives. Energy Sources, 20:427-453.

Dincer, I.

2000. Renewable energy and sustainable development: a crucial review. Renewable and Sustainable Energy Reviews, 4:157-175.

Dincer, I. and M. A. Rosen

2011. Thermal Energy Storage: Systems and Applications. Wiley.

Doughty, C., G. Hellström, and C. F. Tsang

1982. A dimensionless parameter approach to the thermal behavior of an aquifer thermal energy storage sytem. Water Resources Research, 18:571-587. 
Driesner, T.

2007. The system $\mathrm{h}_{2} \mathrm{O}$-nacl ii. correlations for molar volume, enthalpy, and isobaric heat capacity from 0 to 1000 degrees c, 1 to 5000 bar, and 0 to $1 \mathrm{x}_{\mathrm{NaCl}}$. Geochimica et Cosmochimica Acta, 71:4902-4919.

Drijver, B.

2011. High temperature aquifer thermal energy storage (ht-ates): Water treatment in practice. In $\underline{1^{e} \text { Nationaal }}$ Congres Bodemenergie, Utrecht, Nederland, 13-14 Oktober 2011.

Drijver, B., M. V. Aarssen, and B. de Zwart

2012. High-temperature aquifer thermal energy storage (ht-ates): sustainable and multi-usable. In Innostock 2012. $12^{\text {th }}$ International Conference on Energy Storage.

Faessler, J., B. M. Lachal, L. Quiquerez, and S. S. I. de Genève

2015. Géothermie de moyenne profondeur: Scénarios d'utilisation de la ressource via des réseaux de chauffage à distance - Enjeux et principaux enseignements. Genève: Services Industriels de Genève.

Fleuchaus, P., B. Godschalk, I. Stober, and P. Blum

2018. Worldwide application of aquifer thermal energy storage - a review. Renewable and Sustainable Reviews, 94:861-876.

GeoMolTeam

2015. GeoMol - Assessing subsurface potentials of the Alpine Foreland Basins for sustainable planning and use of natural resources. Bayerisches Landesamt für Umwelt.

Hähnlein, S., P. Bayer, and P. Blum

2010. International legal status of the use of shallow geothermal energy. Renewable and Sustainable Energy Reviews, 14:2611-2625.

Hähnlein, S., P. Bayer, G. Ferguson, and P. Blum

2013. Sustainability and policy for the thermal use of shallow geothermal energy. Energy Policy, 59:914-925.

Hartog, N., B. Drijver, I. Dinkla, and M. Bonte

2013. Field assessment of the impacts of aquifer thermal energy storage (ates) systems on chemical and microbial groundwater composition. In Proceeding of the European Geothermal conference. Pisa, Italy.

HeatStore

. Geothermica - era net cofund heatstore (project n.170153-4401).

Hellström, G., C. Tsang, and J. Claesson

1979. Heat storage in aquifers: buoyancy flow and thermal stratification problems.

Hooker, J. and M. Weidmann

2007. A diverse rodent fauna from the middle bartonian (eocene) of les alleveys, switzerland: snapshot of the early theridomyid radiation. Swiss Journal of Geosciences, 100:469-493.

Jenne, E., O. Andersson, and A. Willemsen

1992. Well, hydrology and geochemistry problems encountered in ates systems and their solutions. 
Jesußek, A., S. Grandel, and A. Dahmke

2012. Impacts of subsurface heat storage on aquifer hydrogeochemistry. Energy, 69:1999-2012.

Kappelmeyer, O. and R. Haenel

1974. Geothermics with special reference to application. Stuttgart, Germany: Schweizerbart Science Publishers.

Kim, J., W. Yoon, J. Jeon, M. Koo, and Y. Keehm

2010. Numerical modeling of aquifer thermal energy storage system. Energy, 35:4955-4965.

Krogstad, S., K.-A. Lie, O. Møyner, H. M. Nilsen, X. Raynaud, and B. Skaflestad

2015. Mrst-ad-an open-source framework for rapid prototyping and evaluation of reservoir simulation problems.

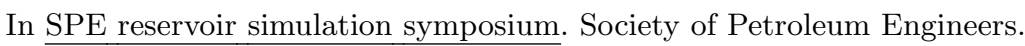

Kuhlemann, J. and O. Kempf

2002. Post-eocene evolution of the north alpine foreland basin and its response to alpine tectonics. Sedimentary Geology, 152:45-78.

Leamon, G. R.

2006. Petroleum well costs. Master's thesis, School of Petroleum Engineering, The University of New South Wales, Sydney, N.S.W., Australia.

Lee, K. S.

2010. A review on concepts, applications, and models of aquifer thermal energy storage systems. Energies, 3:1320-1334.

Lie, K.-A.

2019. An Introduction to Reservoir Simulation Using MATLAB/GNU Octave: User guide for the MATLAB Reservoir Simulation Toolbox (MRST). Cambridge University Press.

Lie, K.-A., S. Krogstad, I. S. Ligaarden, J. R. Natvig, H. M. Nilsen, and B. Skaflestad

2012. Open source MATLAB implementation of consistent discretisations on complex grids. Comput. Geosci., 16:297-322.

Lund, H., P. A. Østergaard, M. Chang, S. Werner, S. Svendsen, P. Sorknæs, J. E. Thorsen, F. Hvelplund, B. O. G. Mortensen, B. V. Mathiesen, C. Bojesen, N. Duic, X. Zhang, and B. Møller

2018. The status of $4^{\text {th }}$ generation district heating: Research and results. Energy, 164:147-159.

Lund, H., S. Werner, R. Wiltshire, S. Svendsen, J. E. Thorsen, F. Hvelplund, and B. V. Mathiesen

2014. $4^{\text {th }}$ generation district heating (4gdh). integrating smart thermal grids into future sustainable energy systems. Energy, 68:1-11.

Makhloufi, Y., E. Rusillon, M. Brentini, A. Moscariello, M. Meyer, and E. Samankassou

2018. Dolomitization of the upper jurassic carbonate rocks in the geneva basin, switzerland and france. Swiss Journal of Geosciences.

McCann, T., C. Pascal, M. Timmerman, P. Krzywiec, J. López-Gómez, L. Wetzel, C. Krawczyk, H. Rieke, and 
J. Lamarche

2006. Post-variscan (end carboniferous-early permian) basin evolution in western and central europe. Geological Society London Memoirs, 35:355-388.

Molz, F., J. Melville, O. Güven, and A. Parr

1983a. Aquifer thermal energy storage: An attempt to counter free thermal convection. Water Resources

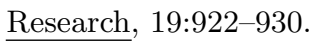

Molz, F., J. Melville, A. Parr, D. King, and M. Hopf

1983b. Aquifer thermal energy storage: A well doublet experiment at increased temperatures. Water Resources

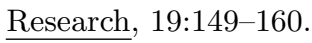

Molz, F., A. Parr, P. Andersen, and V. Lucido 1979. Thermal energy storage in a confined aquifer: Experimental result. Water Resources Research, 15:15091514.

Moscariello, A., A. Pugin, W. Wildi, C. Beck, E. Chapron, M. De Batist, S. Girardclos, S. Ivy Ochs, A.-M. Rachoud-Schneider, and C. Signer

1998. Déglaciation würmienne dans des conditions lacustres à la terminaison occidentale du bassin lémanique (suisse occidentale et france). Eclogae Geologicae Helvetiae, 91:185-201.

\section{OFEV}

2009. Exploitation de la chaleur tirée du sol et du sous-sol. Office fédéral de l'environnement OFEV.

O’Sullivan, M. J., K. Pruess, and M. J. Lippmann

2000. Geothermal reservoir simulation: the state-of-practice and emerging trends. In Proceeding World Geothermal Congress 2000.

\section{PGG}

2011. Evaluation du potentiel géothermique du canton de Genève. Etat de Genève.

Platt, N. H. and B. Keller

1992. Distal alluvial deposits in a foreland basin setting - the lower freshwater molasse (lower miocene), switzerland: sedimentology, architecture and palaeosols. Sedimentology, 39:545-565.

Possemiers, M., M. Huysmans, and O. Batelaan

2014. Influence of aquifer thermal energy storage on groundwater quality: A review illustrated by seven case studies from belgium. Journal of Hydrology: Regional Studies, 2:20-34.

Pruess, K., C. Oldenburg, and G. Moridis

1999. TOUGH2 User's Guide, Version 2.0. Lawrence Berkeley National Laboratory.

Quiquerez, L.

2017. Décarboner le système énergétique à l'aide des réseaux de chaleur: état des lieux et scénarios propectifs pour le canton de Genève. PhD thesis. 
Quiquerez, L., J. Faessler, M. Bernard, and S. I. de Genève

2015. Réseaux thermiques multi-ressources efficients et renouvelables: Etude de cas de la connexion des réseaux thermiques CADIOM (chaleur fatale) et CADSIG (gaz) à Genève et perspectives d'évolution. Genève: Services Industriels de Genève.

Quiquerez, L., J. Faessler, and B. M. Lachal

2016. Valorisation de la chaleur renouvelable et des rejets thermiques: bilan et enjeux de l'interconnexion des deux plus grands réseaux thermiques genevois. Bulletin de l'ARPEA, 269:25-31.

Ramsay, J. G.

1963. Stratigraphy, structure and metamorphism in the western alps. Proceedings of the Geologists' Association, $74: 357-390$.

Rusillon, E.

2017. Characterisation and rock typing of deep geothermal reservoirs in the Greater Geneva Basin (Switzerland \& France. PhD thesis.

Rybach, L.

1992. Geothermal potential of the swiss molasse basin. Eclogae Geologicae Helvetiae, 85:733-744.

Sanner, B.

1999. High temperature underground thermal energy storage. state-of-the-art and prospects.

Schüppler, S., P. Fleuchaus, and P. Blum

2019. Techno-economic and environmental analysis of an aquifer thermal energy storage (ates) in germany. Geothermal Energy, 7:11:24.

Signer, C. and G. E. Gorin 1995. New geological observations between the jura and the alps in the geneva area, as derived from reflection seismic data. Eclogae Geologicae Helvetiae, 88:235-265.

Signorelli, S., N. Andenmatten Berthoud, and T. Kohl

2004. Geothermischer Ressourcenatlas der Schweiz. Erarbeitung und Bewertung des geothermischen Potentials der Schweiz. Bundesamts für Energie BFE.

Sommaruga, A.

1997. Geology of the Central Jura and the Molasse Basin: new insight into an evaporite-based foreland fold and thrust belt. PhD thesis.

Sommaruga, A.

1999. Décollement tectonics in the jura foreland fold-and-thrust belt. Marine and Petroleum Geology, 16:111134.

Sommer, W., J. Valstar, P. V. Gaans, and H. Rijnaarts

2013. The impact of aquifer heterogeneity on the performance of aquifer thermal energy storage. Water Resources Research, 49:8128-8138. 
Sommer, W., J. Valstar, I. Leusbrock, T. Grotenhuis, and H. Rijnaarts

2015. Optimization and spatial pattern of large-scale aquifer thermal energy storage. Applied Energy, 137:322337.

Sowers, L., K. York, and L. Stiles

2006. Impact of the thermal build up on groundwater chemistry and aquifer microbes. In Proceedings of Ecostock, Pomena, $31^{\text {th }}$ May - $2^{\text {nd }}$ June, Pp. 1-7.

Spivey, J., W. McCain, and R. North

2004. Estimating density, formation volume factor, compressibility, methane solubility, and viscosity for oilfield brines at temperatures from 0 to 275 oc, pressures to $200 \mathrm{mpa}$, and salinities to $5.7 \mathrm{~mole} / \mathrm{kg}$. Journal of Canadian Petroleum Technology.

Trümpy, R.

1980. Geology of Switzerland - a guide-book. Part A: An outline of the geology of Switzerland. Part B: Geological excursions. Wepf and Co.

Van Lopik, J. H., N. Hartog, and W. J. Zaadnoordijk

2016. The use of salinity contrast for density difference compensation to improve the thermal recovery efficiency in high-temperature aquifer thermal energy storage systems. Hydrogeol J., 24:1255-1271.

Wilson, M., E. Neumann, G. Davies, M. Timmerman, M. Heeremans, and B. Larsen

2004. Permo-carboniferous magmatism and rifting in europe: introduction. Geological Society London Special Publications, 223:1-10.

Winterleitner, G., F. Schütz, C. Wenzlaff, and E. Huenges

2018. The impact of reservoir heterogeneities on high-temperature aquifer thermal energy storage systems. a case study from northern oman. Geothermics, 74:150-162. 